\title{
Hallazgos de imagen en Covid-19. Complicaciones y enfermedades simuladoras
}

Jaime Álvarez C. ${ }^{\star}$, Paula Concejo l. ${ }^{1}$, Concepción Ferreiro A. ${ }^{1}$, Esther Gálvez G. ${ }^{1}$, María Azahara Hoyas G. ${ }^{1}$, Iñigo Zubiaguirre T.', Cristian Rodríguez R.', Wilmar Ocampo T.', Francisca Sánchez O.', Manuel Martínez P.'

1. Radiólogo, Servicio de radiodiagnóstico, Hospital Universitario Severo Ochoa, Leganés-Madrid, España.

\section{Imaging finidings in covid-19. Complications and mimickers}

\section{Resumen:}

Ante la situación actual de pandemia producida por el SARS-CoV-2, la comunidad científica está realizando un esfuerzo para compartir el conocimiento de esta enfermedad emergente. Para contribuir a este esfuerzo, hemos realizado una revisión de las historias clínicas y de las pruebas de imagen en pacientes diagnosticados de la COVID-19 en nuestro centro, uno de los más afectados por la pandemia de la Comunidad de Madrid (España). El objetivo de esta revisión es describir las alteraciones radiológicas pulmonares y mostrar la patología extrapulmonar más frecuente y entidades simuladoras de la COVID-19. Los radiólogos deben familiarizarse con estas características de imagen de la COVID-19, de forma que se puedan diseñar protocolos de imagen específicos para cada una de ellas de cara a un diagnóstico y tratamiento oportuno. Palabras clave: Complicaciones; COVID-19; Extrapulmonar; Neumonía; Simuladoras; Trombosis.

Abstract: Given the current pandemic caused by SARS-CoV-2, the scientific community is making an effort to share knowledge of this emerging disease. To contribute to this effort, we have done a comprehensive review of the clinical history and imaging tests in patients affected by COVID-19 in our institution, one of the most affected by the pandemic in the Community of Madrid (Spain). The aim of this review is to describe the radiological findings in the lungs and show the most frequent extrapulmonary pathology as well as some entities that may be confused with COVID-19 will be discussed. Radiologists should become familiar with these imaging features of COVID-19 to design specific imaging protocols that allow prompt diagnosis and treatment.

Keywords: Complications; COVID-19; Extrapulmonary; Mimickers; Pneumonia; Thrombosis.

Álvarez J, et al. Hallazgos de imagen en Covid-19. Complicaciones y enfermedades simuladoras. Rev Chil Radiol 2020; 26(4): 145-162.

*Correo electrónico: Jaime Álavrez C. / jhalvarez05@gmail.com

Trabajo enviado el 01 de junio de 2020. Aceptado para publicación el 17 de agosto de 2020.

\section{Introducción}

La enfermedad respiratoria aguda de coronavirus 2019 (COVID-19, anteriormente conocida como 2019-nCoV) es una enfermedad altamente infecciosa causada por el Coronavirus 2 del síndrome respiratorio agudo grave (SARS-CoV-2) descrita por primera vez en Wuhan, capital de la provincia de Hubei, en China en diciembre del 2019 y se ha propagado a todo el mundo con gran rapidez ${ }^{1}$. El 30 de enero de
2020, la Organización Mundial de la Salud declaró estado de emergencia de Salud Pública de ámbito mundial, y el 11 de marzo fue declarada pandemia ${ }^{2}$. Al 01 de junio de 2020 estaban ya confirmados un total de 6.246.042 casos de la COVID-19 con 374.452 muertes en todo el mundo, de los cuales 239.638 casos con 27.127 muertes correspondían a casos declarados en España ${ }^{3}$. 
La Comunidad Autónoma de Madrid ha sido una de las áreas más afectadas. De los casi 50 hospitales de la Comunidad Autónoma de Madrid, nuestro centro, el Hospital Severo Ochoa, ha sido uno de los más los que ha recibido mayor cantidad de casos, asiste a una población de 190.000 personas y atendió a 3.562 pacientes por la COVID-19, de los que 2.699 fueron ingresados, llegando a cuadriplicarse durante la pandemia el número máximo de pacientes ingresados para los que está previsto el hospital.

Hemos realizado una revisión de las historias clínicas y de las pruebas de imagen realizadas a los pacientes atendidos por la COVID-19 en nuestro hospital, centrándonos en los hallazgos radiológicos de las complicaciones extrapulmonares y en la detección de patologías asociadas. Se incluyen también entidades que pueden simular afectación por la COVID-19 en imagen y provocar errores diagnósticos.

La revisión estará estructurada en las siguientes secciones:

1. Patrones de afectación pulmonar. 2. Afectación extrapulmonar. 3. Complicaciones relacionadas con un estado protrombótico (fenómenos trombóticos y embólicos). 4. Complicaciones relacionadas con el tratamiento anticoagulante. 5. Enfermedades simuladoras.

\section{Patrones de la afectación pulmonar}

La nueva epidemia de la COVID-19 se asocia principalmente a patología pulmonar pese a que las comorbilidades respiratorias preexistentes asociadas son un factor de riesgo de los menos importantes comparadas con la HTA, cardiopatías, obesidad, sexo varón o edad ${ }^{4,5}$. El patrón típico de la afectación pulmonar es la presencia de opacidades en vidrio deslustrado (vidrio esmerilado) periféricas y sub- pleurales en segmentos posteriores de los lóbulos inferiores (sello distintivo cardinal de la COVID-19) con evolución a consolidaciones parcheadas subsegmentarias principalmente subpleurales ${ }^{5}$. Además, se han descrito otras formas de afectación como el patrón en empedrado, signo de halo y formación de bandas subpleurales ${ }^{5,6}$. En la figura 1 se describen los principales patrones radiológicos por tomografía computarizada (TC) de la afectación pulmonar.

\section{Afectación extrapulmonar}

Se han identificado casos de neumomediastino y neumotórax asociado a la afectación pulmonar por la COVID-19 aunque se desconoce el mecanismo. Una vez que se observan estas complicaciones, estos pacientes tienen que ser vigilados estrechamente porque puede ser un posible indicador de empeoramiento de la enfermedad. Por lo tanto, el diagnóstico temprano por imagen y el tratamiento oportuno de las complicaciones de la COVID-19 pueden mejorar el efecto terapéutico y reducir la mortalidad?.

\section{Neumomediastino}

El neumomediastino espontáneo se define por la presencia de gas extraluminal en el mediastino de origen no traumático sin enfermedad pulmonar asociada. Se trata de un cuadro autolimitado y el pronóstico depende de la causa subyacente ${ }^{8}$. La presencia de aire en el mediastino se explica por disección por el aire que se extiende de manera centrípeta por las vainas broncovasculares, estructuras serosas y tejido adiposo por un aumento de la presión intratorácica que condiciona rotura alveolar ${ }^{8,9}$. La rotura alveolar ocurre en presencia de presión intraalveolar elevada o daño a las paredes alveolares.
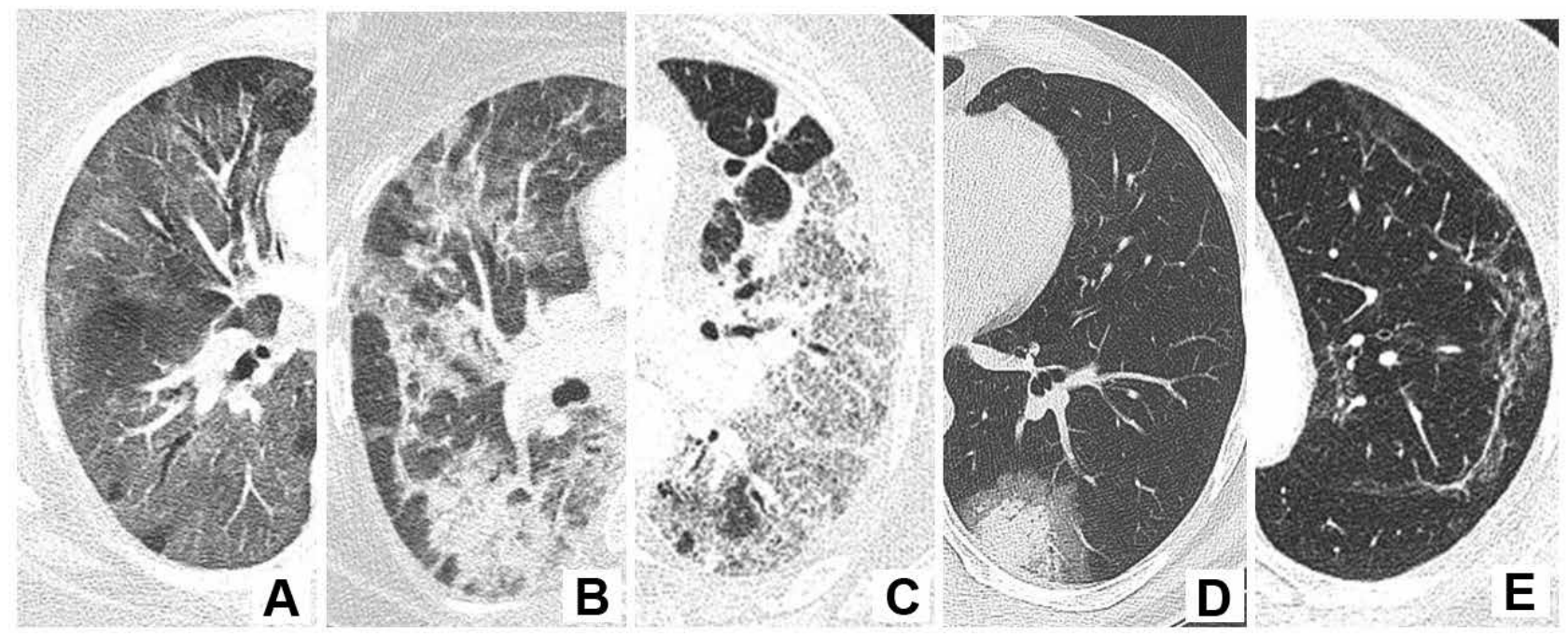

Figura 1: Patrones típicos de TC de tórax de la afectación viral COVID-19: a. Opacidades en vidrio deslustrado. b. Consolidaciones. c. Patrón en empedrado. d. Signo del halo. e. Bandas subpleurales. 
La radiografía de tórax es la prueba de imagen de rutina para el diagnóstico del neumomediastino visualizado como una doble línea que dibuja el contorno mediastínico. La TC es la prueba gold standard, aunque se reserva para casos dudosos o complicados (Figura 2$)^{8}$.

La ventilación con protección pulmonar, la ventilación en posición prona, la sedación y la analgesia adecuadas son parte del manejo de los pacientes con la COVID-19. Aproximadamente el $3.2 \%$ de los pacientes requieren intubación y ventilación invasiva en algún momento del curso de la enfermedad ${ }^{10}$. El barotrauma ocurre como complicación común en los pacientes sometidos a ventilación mecánica y a la inserción de catéter venoso central, consiste en la rotura de alvéolos como consecuencia de una sobreexpansión pulmonar, con salida de aire alveolar y formación finalmente de neumomediastino, neumotórax y enfisema (Figura 3) ${ }^{11}$.

\section{Neumotórax}

Se ha descrito una asociación entre la COVID-19 y el neumotórax espontáneo, pero se desconoce su importancia pronóstica ${ }^{12}$, en nuestro centro no identificamos casos de neumotórax espontaneo.
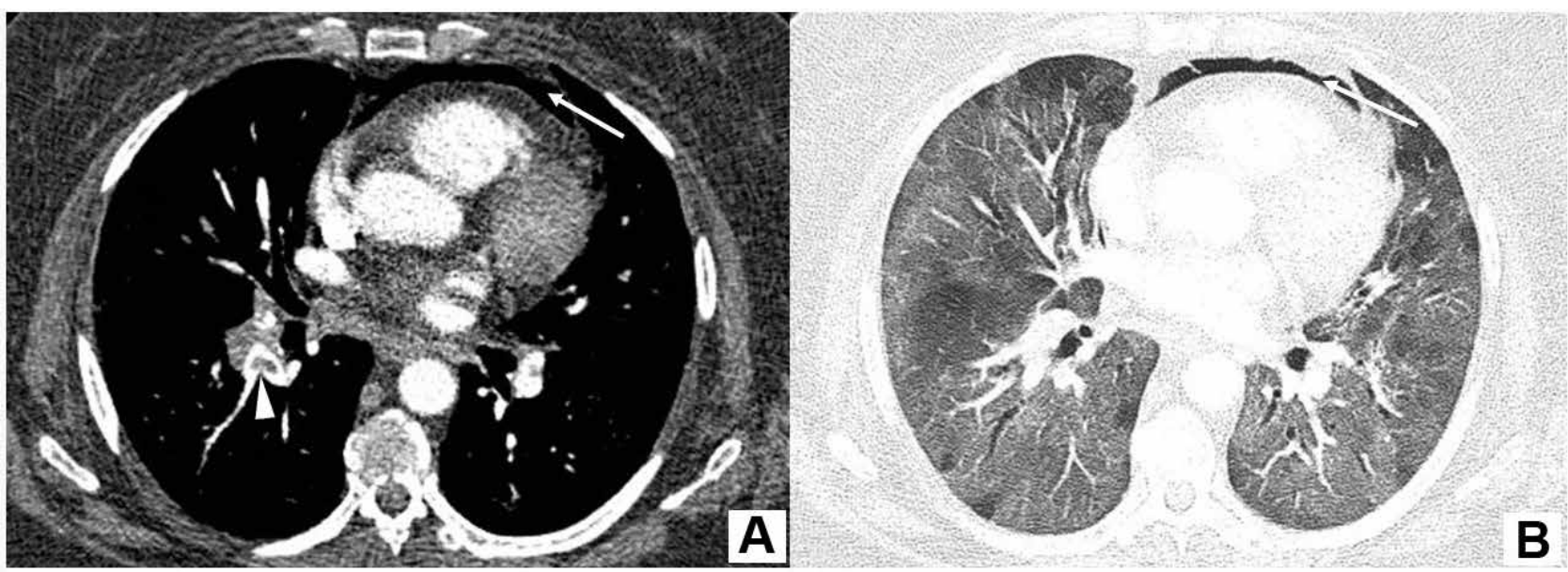

Figura 2: Mujer de 65 años con afectación pulmonar por la COVID-19. Al tercer día del ingreso presenta empeoramiento clínico y analítico con aumento de LDH y Dímero-D. AngioTAC de tórax, ventana mediastino (a) y pulmonar (b) evidencia tromboembolismo pulmonar unilateral derecho (punta de flecha), neumomediastino (flechas) y opacidades en vidrio deslustrado bilaterales difusas multifocales.
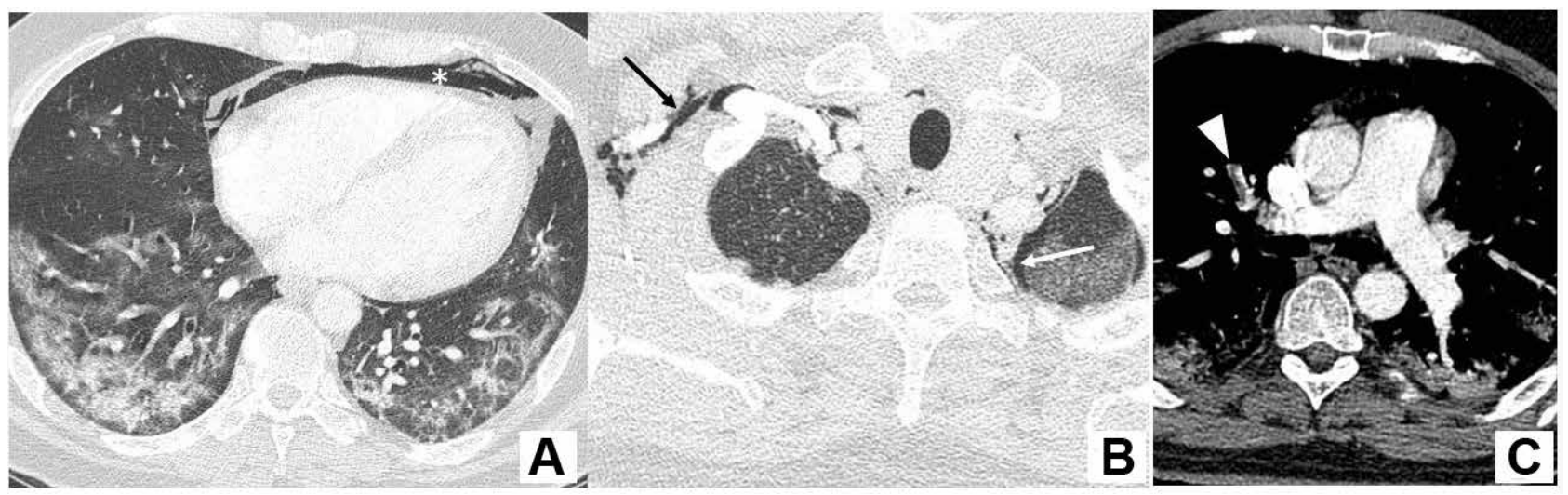

Figura 3: Varón de 49 años, obeso, con neumonía COVID-19, presenta inicio súbito de disnea y elevación de Dímero-D. AngioTAC de tórax, ventana de pulmón (a y b) y mediastino (c); evidencia tromboembolismo pulmonar unilateral derecho (punta de flecha), neumomediastino $\left(^{\star}\right)$, enfisema subcutáneo (flecha negra), mínimo neumotórax izquierdo (flecha blanca) y opacidades en vidrio deslustrado bilaterales multifocales con afectación pulmonar en torno al $50 \%$. 
El neumotórax puede ser espontáneo primario (sin causa conocida subyacente) o secundario a enfermedad pulmonar preexistente. La rotura espontánea de una bulla subpleural es la causa más frecuente del espontáneo primario y la mayoría de los secundarios son iatrogénicas por punción aspiración, toracocentesis y presión positiva. Generalmente con la visualización del aire libre en el estudio radiográfico es suficiente para el diagnóstico, aunque en neumotórax de pequeño tamaño o en pacientes en estado crítico el diagnóstico puede requerir la realización de $\mathrm{TC}^{13}$.

\section{Complicaciones relacionada con un estado protrombótico}

Conforme se conoce más acerca de la fisiopatología de la infección COVID-19 se explican algunos de los hallazgos asociados o complicaciones que se ven en estos pacientes. La infección se relaciona con un estado protrombótico identificándose y niveles elevados de Dímero- $D^{14}$. Se ha postulado que este estado protrombotico sea secundario a una liberación de citocinas proinflamatorias que inducen la activación de células endoteliales y mononucleares con expresión del factor tisular que conduce a la activación de la coagulación y a la generación de trombina. La circulación de trombina libre, no controlada por anticoagulantes naturales, puede activar las plaquetas y provocar trombosis ${ }^{15}$. Las tasas de eventos tromboembólicos y el uso de aumentado de la tromboprofilaxis en pacientes con la COVID-19 son, por lo tanto, un tema de gran interés. Sin embargo, las manifestaciones clínicas de esta tendencia procoagulante están poco definidas ${ }^{14,15}$.

\section{Tromboembolismo pulmonar (TEP)}

Se ha descrito una mayor prevalencia de tromboembolismo pulmonar (TEP) en pacientes afectados por la COVID-19, de hasta un $23 \%$, con una mayor incidencia a los 12 días del inicio de los síntomas. No se ha visto clara asociación entre la extensión de la afectación pulmonar y riesgo de desarrollar fenómenos trombóticos, pero sí en pacientes con mala evolución clínica de la infección ${ }^{16}$. Ante un paciente con hipoxia y valores de Dímero-D en aumento mientras el resto de los parámetros analíticos se normalizan (ferritina, $\mathrm{LDH}$, proteína $\mathrm{C}$ reactiva) habría que sospechar complicación con TEP ${ }^{17}$.Las guías actuales recomiendan la TC de tórax como herramienta diagnóstica para valorar el patrón de afectación y la extensión pulmonar. Sin embargo, debido a la creciente incidencia de TEP por coagulopatía asociada con la infección por SARS-CoV-2, algunos autores proponen realizar AngioTAC de tórax para evaluar el pulmón y la presencia de trombo (Figura 4) ${ }^{18}$, así como para evaluar otras complicaciones como la sobrecarga de cavidades derechas (Figura 5) que pueden resultar en dificultad respiratoria, sobre todo en aquellos pacientes con factores de riesgo (pacientes ingresados en $\mathrm{UCl}$, ventilación mecánica, etc. $)^{16,18}$.

El tratamiento inicial suele ser la anticoagulación sistémica hasta que se resuelva el trombo ${ }^{19,20}$. La trombolisis o trombectomía se reserva para pacientes en shock, hipotensión o con otros signos de hipoperfusión sistémica causada por la embolia pulmonar; la cirugía (lobectomía) solo se emplea en aquellos casos que no haya una mejoría clínica, sospecha de gangrena, hemoptisis masiva o necrosis pulmonar ${ }^{19}$.

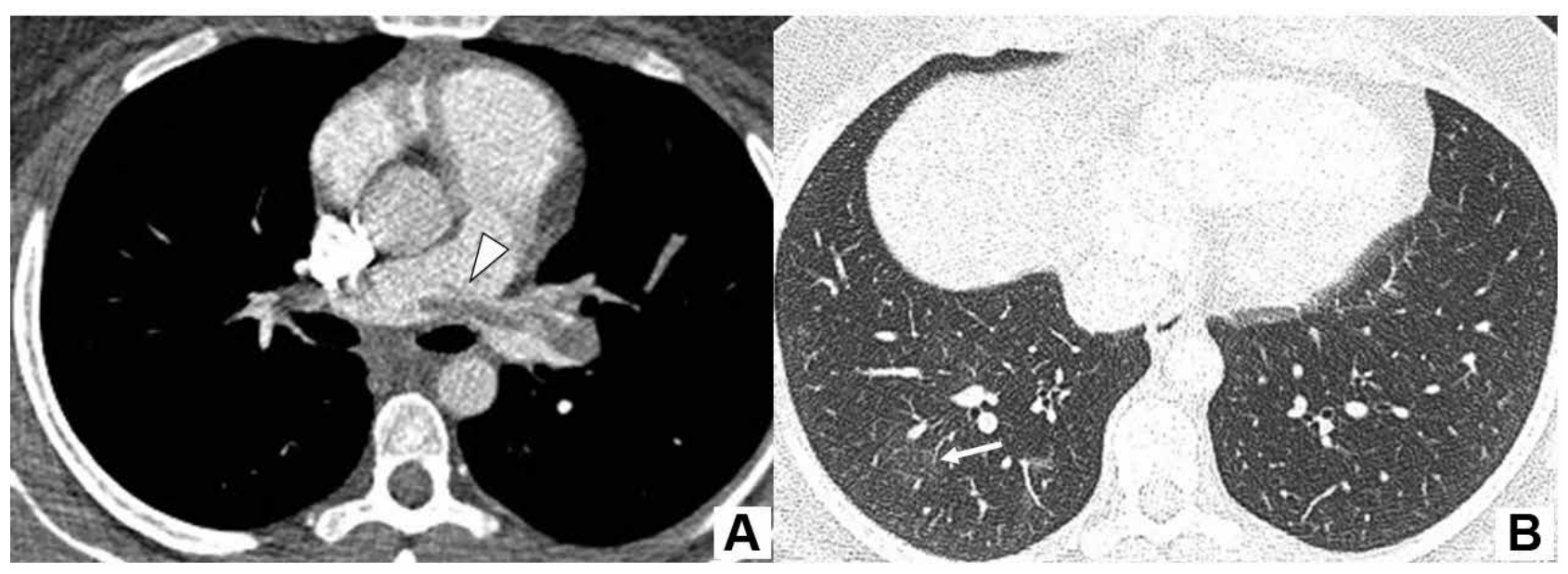

Figura 4: Mujer de 26 años con antecedente de tratamiento con anticonceptivos orales, clínica de tos seca y disnea (sospecha de infección por COVID-19), taquicardia sinusal, patrón ECG S1Q3T3 y elevación de Dímero-D. AngioTAC de tórax, mediastino (a) y pulmón (b); evidencia tromboembolismo pulmonar bilateral con trombo en silla montar (punta de flecha) y sobrecarga cavidades derechas. Tenues opacidades en vidrio deslustrado bilaterales con afectación pulmonar en torno al $25 \%$ (flecha). 


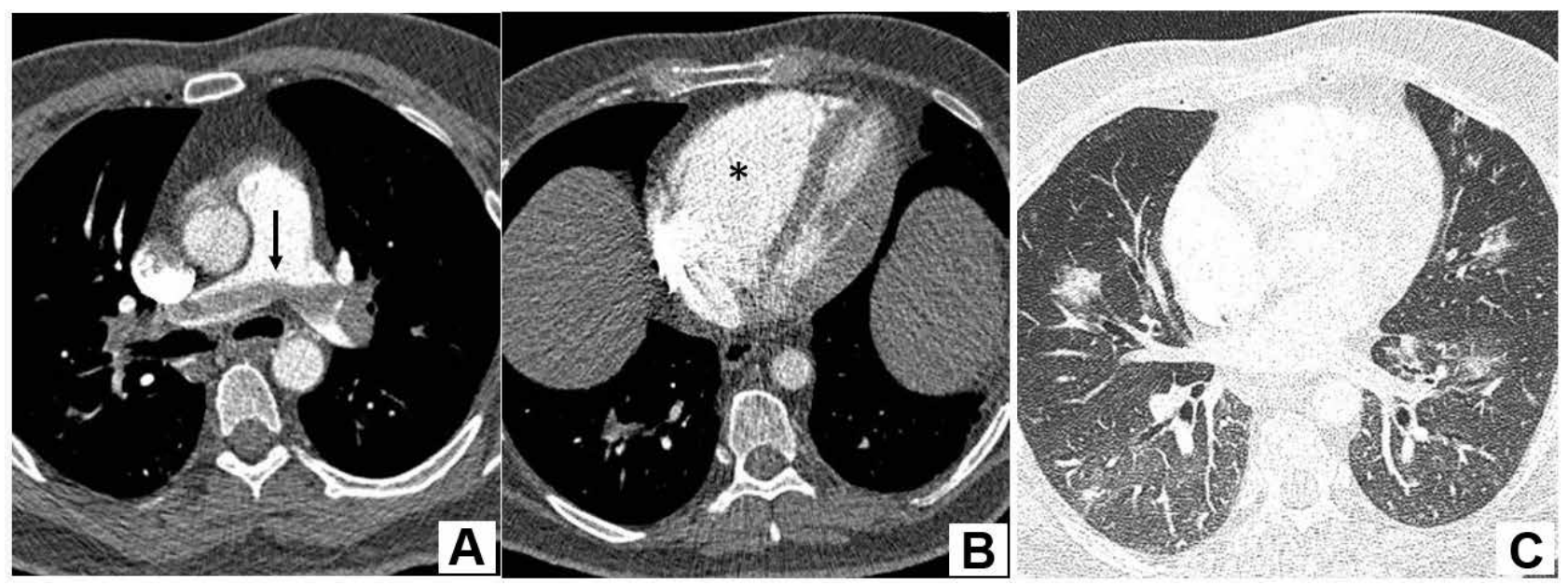

Figura 5: Varón de 50 años con factores de riesgo cardiovascular y hepatopatía crónica, acude por un cuadro de una semana de evolución de tos, dolor centrotorácico, cortejo vegetativo y elevación del Dímero-D. AngioTAC de tórax, mediastino (a,b) y pulmón (c); evidencia tromboembolismo pulmonar bilateral con trombo en silla montar (flechas) y sobrecarga cavidades derechas (*). Opacidades en vidrio deslustrado bilaterales con afectación pulmonar en torno al $25 \%$.

\section{Trombos flotantes aórticos}

Los trombos flotantes aórticos (TFA) son una entidad rara frecuentemente asociada a enfermedad ateroesclerótica y aneurismática ${ }^{21,22}$. En aquellos pacientes sin enfermedad vascular arterial, debido al alto flujo y presión aórtica es rara la presencia de TFA, en estos casos suelen estar asociados a estados de hipercoagulabilidad y enfermedades hematológicas, tras procedimientos instrumentales o tratamiento esteroideo. En general son más frecuentes en la aorta torácica descendente, así como en el arco aórtico (Figura 6) ${ }^{21,22,23}$. La prueba de elección es la AngioTAC por su amplia disponibilidad y puesto que permite valorar la aorta en toda su extensión, troncos supraaórticos, así como los vasos pulmonares y la existencia de fenómenos isquémicos embólicos concomitantes en otras localizaciones ${ }^{21,22}$. Debido al alto riesgo embolígeno es fundamental el tratamiento, aunque no hay un protocolo establecido, siendo el tratamiento médico (anticoagulación y fármacos trombolíticos) la primera opción terapéutica reservando la cirugía (trombectomía, tromboendarterectomía y el reemplazo aórtico) o colocación de prótesis endovasculares para aquellos casos que no mejoren con el tratamiento médico o cuando haya recurrencias o aquellos pacientes con factores de riesgo ${ }^{21,22,23}$.

\section{Trombosis venosa profunda y tromboflebitis}

Se sabe que los pacientes en $\mathrm{UCI}$ son de mayor riesgo al desarrollo de trombosis venosa profunda (TVP); en ausencia de una profilaxis adecuada, su incidencia general entre los pacientes hospitalizados es del $0,9 \%$, llegando hasta el $15 \%$ al $32 \%$ entre los pacientes de $\mathrm{UCl}^{24,25}$. Esta incidencia aumenta en pacientes con la enfermedad COVID-19 siendo la localización más frecuente del trombo principalmente distales en territorios gemelares e infrapoplíteos, también se describen en el eje ilíaco-femoral-poplíteo

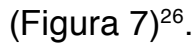

Las infecciones agudas se asocian con un aumento transitorio del riesgo de eventos tromboembólicos venosos ${ }^{27}$, se postula que la producción de factores procoagulantes como el factor tisular y factores de la degradación del coagulo como el Dímero-D, sean mecanismos posibles de trombosis, aunque no se ha establecido una relación con la TVP ${ }^{26}$. Otro factor favorable posible que también pudiese explicar la afectación de las extremidades superiores, entre ellas la tromboflebitis de la vena yugular externa (Figura 8) es el uso de un ventilador de presión positiva continua en las vías respiratorias, que puede comprimir los vasos superficiales o profundos de las extremidades superiores ${ }^{26}$; todos los pacientes en nuestro hospital con afectación de las extremidades superiores, de hecho, estaban recibiendo terapia de presión positiva continua, además algunos de ellos eran portadores de vías centrales.

La ecografía suele ser el estudio inicial, sobre todo en los pacientes con vías centrales. Se comportan como cualquier estructura venosa trombosada. En los estudios de TC o RM con contraste, la vena trombosada está aumentada de tamaño y con una captación periférica que corresponde a la pared venosa $^{28}$ 

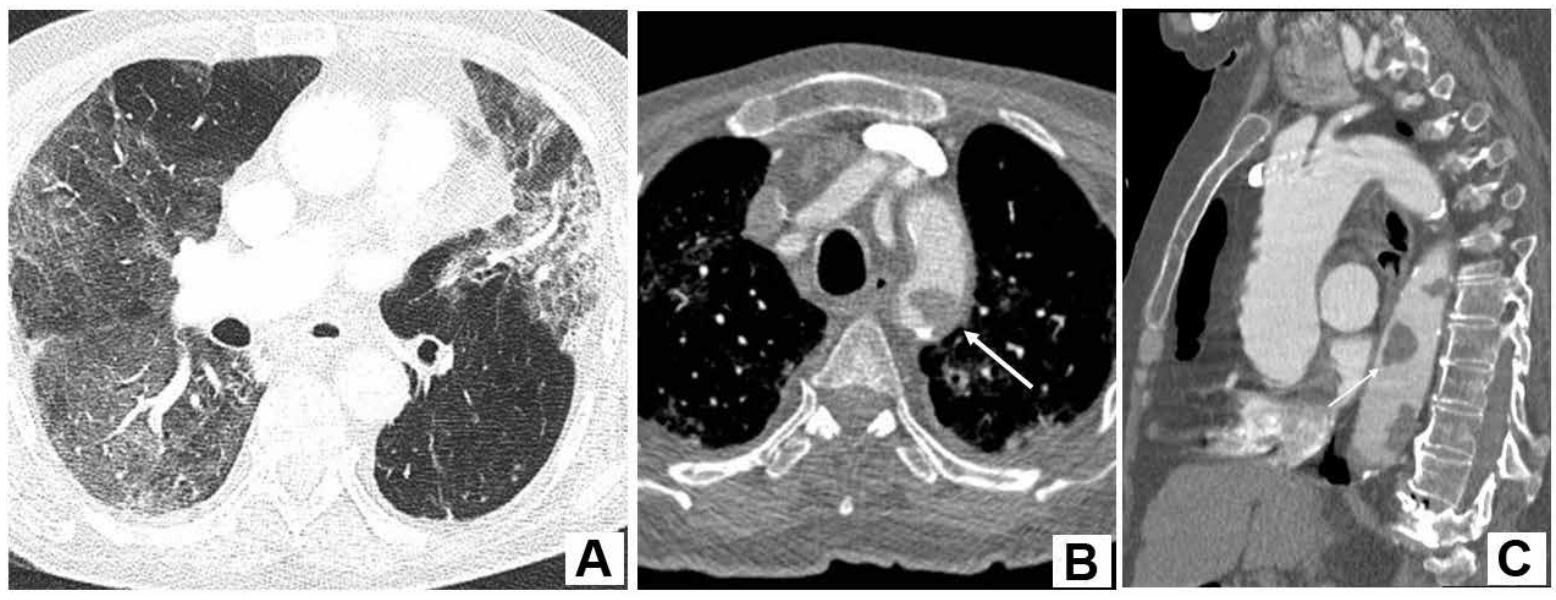

Figura 6: Varón de 89 años con diagnóstico de COVID-19 con evolución tórpida y aumento del Dímero-D. AngioTAC de tórax, ventana de pulmón (a); Opacidades en vidrio deslustrado con afectación del parénquima pulmonar del 50-75\%. Ventana de mediastino corte axial (b) y coronal (c) trombos flotantes en cayado aórtico y aorta torácica descendente (flechas).
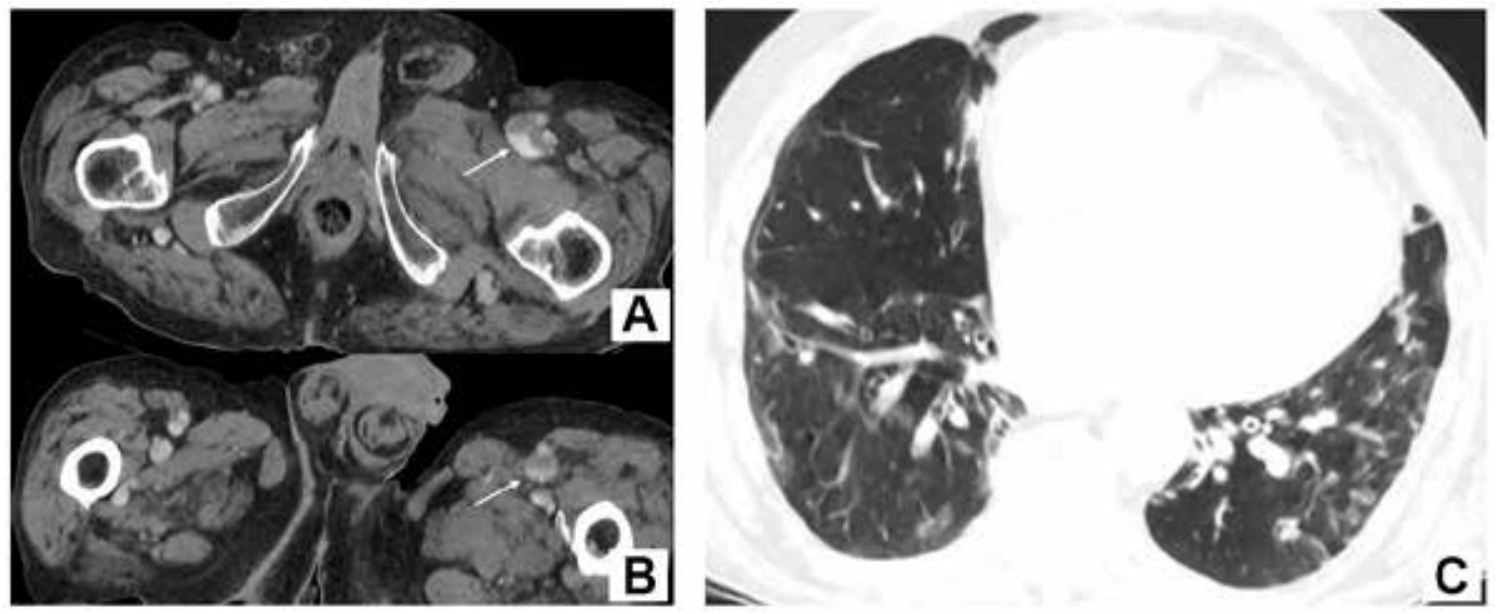

Figura 7: Varón de 77 años con diagnóstico de COVID-19 con evolución tórpida y aumento del Dímero-D. TC de abdominopélvico con contraste iv (a.) defecto de repleción de las venas femorales común, superficial y profunda, en relación con TVP. (flechas). TC de tórax, ventana de pulmón (b); Opacidades en vidrio deslustrado con afectación pulmonar en torno al $25 \%$.
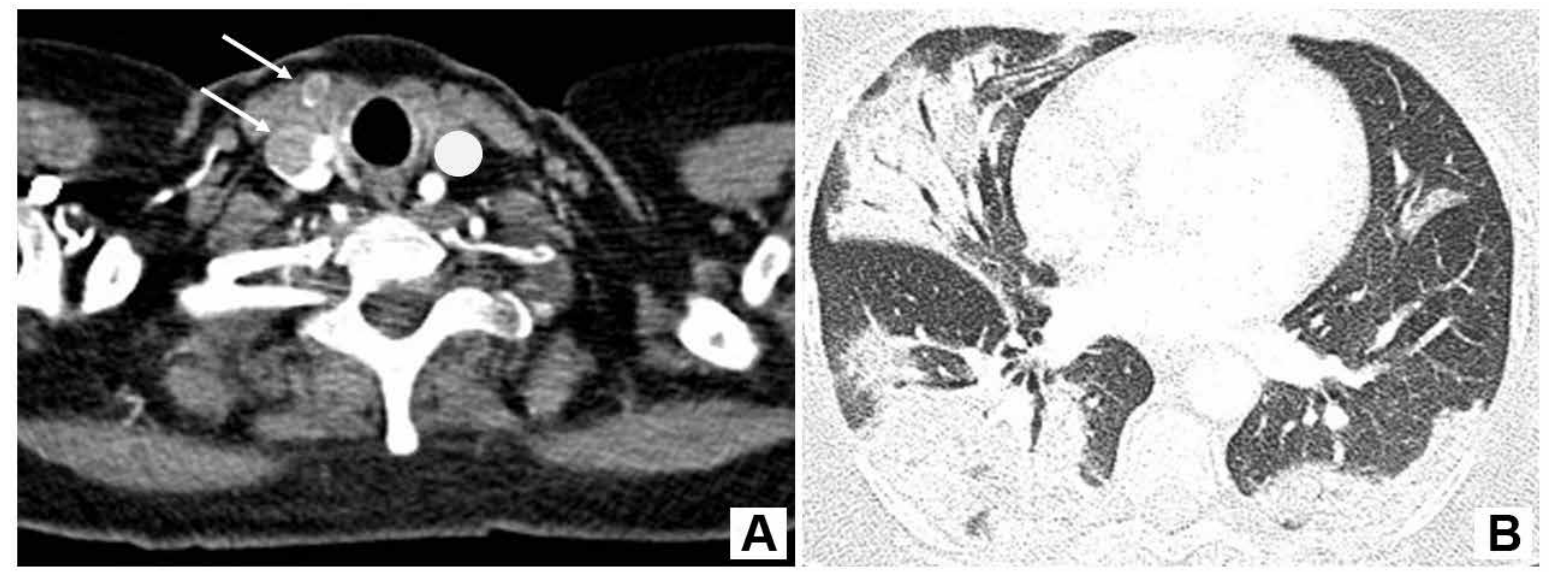

Figura 8: Mujer de 48 años sin antecedente de interés con clínica de tos seca y disnea (sospecha de infección por COVID-19) y elevación de Dímero-D. AngioTAC de tórax, ventana de mediastino (a.) evidencia defecto de repleción en vena yugular anterior e interna derecha compatible con trombosis (flechas). Ventana de pulmón (b); se observan consolidaciones parenquimatosas múltiples predominantes en LID. 
Desafortunadamente, todavía no hay datos disponibles sobre el pronóstico de los pacientes que desarrollan TVP durante una infección por SARS-COV-2 por lo que estudios adicionales deben investigar cómo interactúan las dos condiciones entre sí y su posible afectación en la recuperación. Sin embargo, considerando estos datos preliminares, en nuestra institución se administra dosis anticoagulantes de heparina de bajo peso molecular (HBPM) en pacientes hospitalizados con la COVID-19, después de monitorizar los resultados de las pruebas de coagulación y la función renal y hepática ${ }^{26}$.

\section{Accidente cerebrovascular isquémico}

Aunque el accidente cerebrovascular isquémico se ha reconocido como una complicación de la COVID-19 (generalmente con enfermedad grave) ${ }^{29}$ los mecanismos y el fenotipo aún no son definitivos, aunque se ha sugerido que la COVID-19 podría estimular la producción de anticuerpo antifosfolípido ${ }^{30}$ como mecanismo de accidente cerebrovascular isquémico (Figura 9).

La anticoagulación terapéutica temprana con HBPM también podría ser beneficiosa para reducir la tromboembolia en pacientes con accidente cerebrovascular isquémico asociado con la COVID-19, pero debe equilibrarse con el riesgo de hemorragia intracraneal, incluida la transformación hemorrá- gica del infarto agudo ${ }^{31}$.El diagnóstico precoz y el tratamiento hiperagudo son la clave para minimizar la mortalidad y la morbilidad de los pacientes con accidente cerebrovascular agudo. Las "unidades de ictus" deben tener cuidado con el hecho de que los pacientes con la COVID-19 pueden presentarse con accidentes cerebrovasculares y deben contar con el equipo de protección personal adecuado en cada paciente sospechoso ${ }^{32}$.

\section{Infartos cerebrales múltiples}

Existen informes globales emergentes de coagulopatía en el contexto de la COVID-19, que incluyen embolia pulmonar, infartos cerebrales múltiples (Figura 10) e isquemia de extremidades ${ }^{33}$. Una publicación reciente identificó anticuerpo antifosfolípido en un paciente con la COVID-19 con coagulopatía significativa. Estos anticuerpos también pueden surgir transitoriamente en pacientes con enfermedades críticas y diversas infecciones.

La presencia de estos anticuerpos rara vez puede conducir a eventos trombóticos que son difíciles de diferenciar de otras causas de trombosis multifocal en pacientes críticos, como la coagulación intravascular diseminada, la trombocitopenia inducida por heparina y la microangiopatía trombótica ${ }^{30}$.

También se ha propuesto que la coagulopatía puede presagiar un mal pronóstico en pacientes con la enfermedad COVID-19.

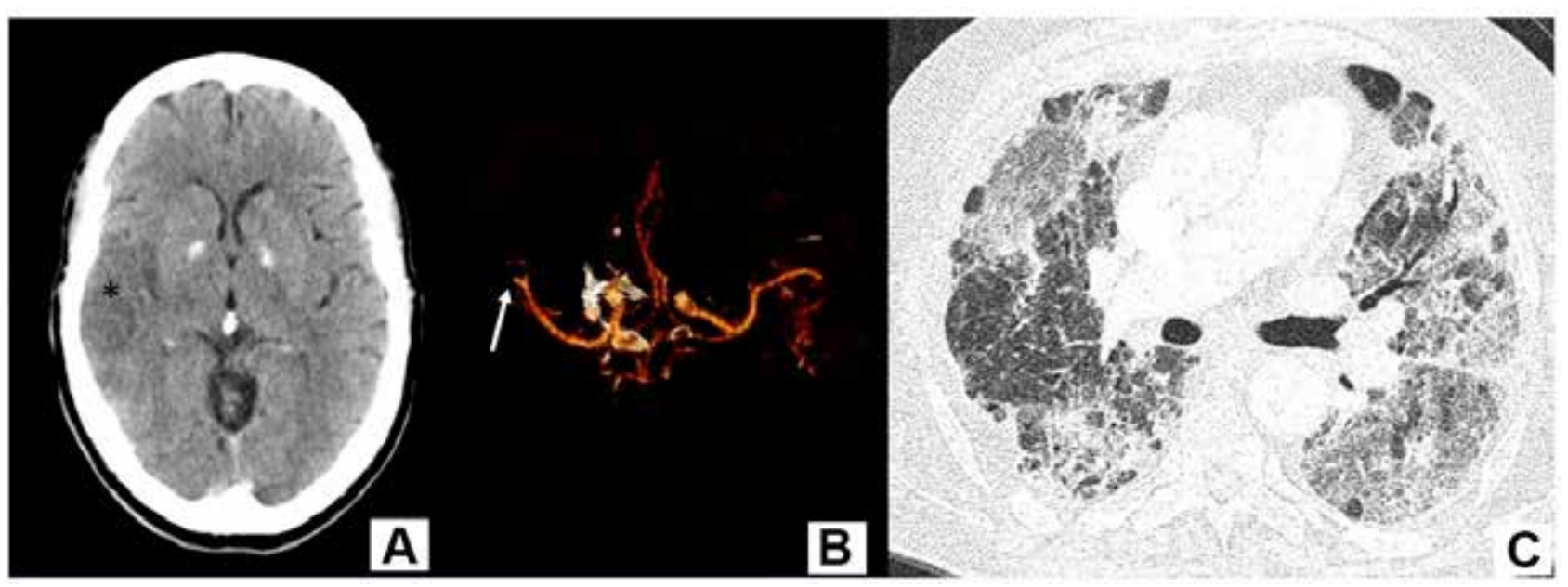

Figura 9: Varón de 77 años con neumonía COVID-19, presenta clínica de paresia facial y braquial izquierda. TC craneal sin contraste iv (a). Lesión hipodensa cortico subcortical en hemisferio cerebral derecho compatible con isquemia aguda en territorio de la arteria cerebral media derecha (*). TC con contraste iv, polígono de Willis con reconstrucción $3 D$ (b) se observa obstrucción del segmento M2 derecho (flecha). TC pulmón ventana de pulmón se aprecian áreas extensas de patrón en vidrio deslustrado y en empedrado bilaterales. 


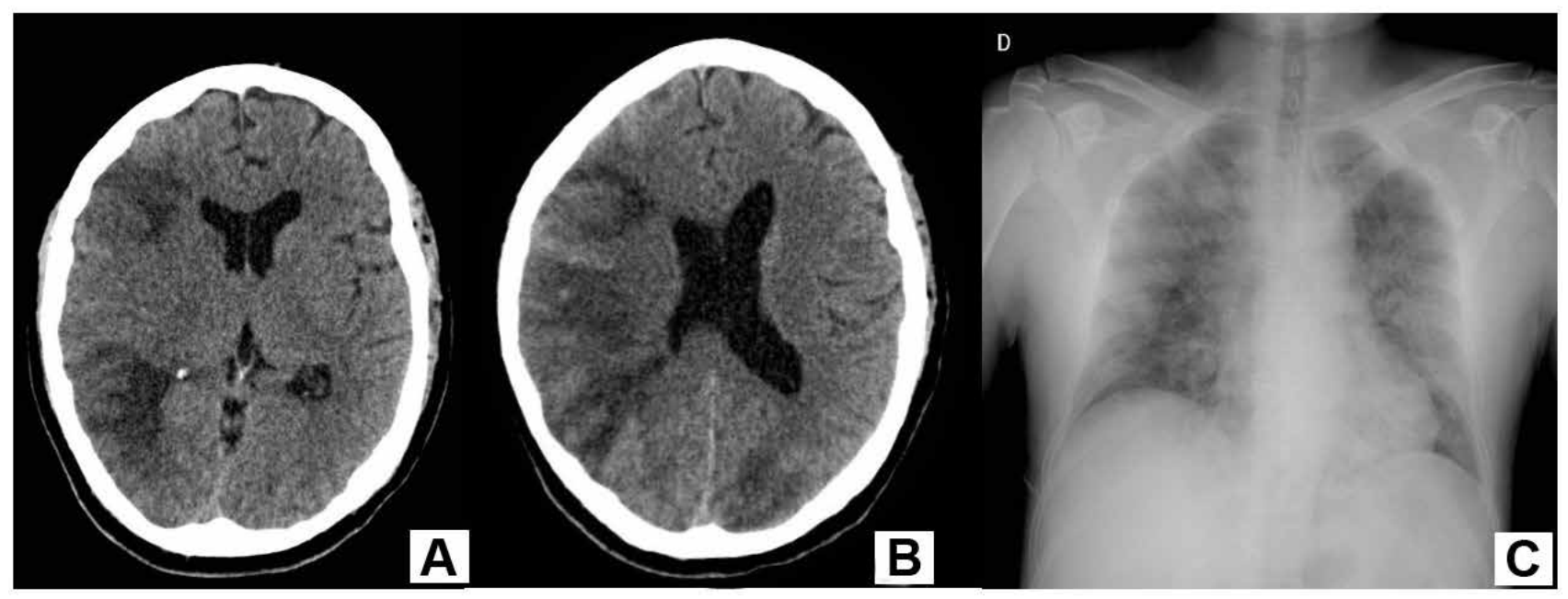

Figura 10: Varón 56 años, SARS-CoV-2 positivo, ingresado en UCl por insuficiencia respiratoria grave, tras retirada de sedación se evidencia clara hemiparesia izquierda con reflejos asimétricos. TC craneal sin contraste iv (a y b). Lesión isquémica en el territorio de arteria cerebral media derecha y arteria cerebral posterior izquierda. Radiografía PA de tórax (c) muestra opacidades parcheadas periféricas bilaterales en ambos hemitórax.

\section{Isquemia mesentérica/ colitis isquémica}

La isquemia intestinal, principalmente la trombosis de las arterias mesentéricas y en menor media la colitis isquémica, es una afección poco frecuente que constituye una de las urgencias abdominales con peor pronóstico y puede ser una complicación tromboembólica secundaria al estado de hipercoagulabilidad que se asocia a la COVID-19. Presenta altas tasas de morbimortalidad, por lo tanto, el diagnóstico precoz y el manejo rápido son imprescindibles ${ }^{34}$. En este sentido, las pruebas de imagen tienen un importante papel, ya que ni los síntomas ni las pruebas de laboratorio son específicos. En la actualidad, la TC es la técnica de imagen inicial de elección para el diagnóstico de sospecha de la isquemia intestinal aguda y, además, permite excluir otras causas de dolor abdominal agudo (Figura 11) ${ }^{35}$. Por último, el intestino delgado también puede ser un sitio importante de entrada o interacción del SARS-CoV-2, ya que los enterocitos son ricos en receptores de enzima convertidora de angiotensina (ACE-2). Los síntomas gastrointestinales iniciales que aparecen temprano durante el curso de la COVID-19 respaldan esta hipótesis ${ }^{36}$.

\section{Lesiones isquémicas de órganos sólidos}

El infarto renal es una entidad infradiagnosticada debido a la presentación clínica y analítica inespecífica. Debido a la amplia disponibilidad de la TC está aumentando el diagnostico incidental de infartos renales lo que favorece un diagnóstico y tratamiento temprano disminuyendo así el tiempo de isquemia renal (Figura 12) ${ }^{37}$. Debido a su baja frecuencia no hay un protocolo establecido de tratamiento. La anticoagulación es insuficiente para disminuir la isquemia por lo que se opta por medidas más agresivas como la trombólisis sistémica, aunque incrementa el riesgo de sangrado. Se han desarrollado técnicas endovasculares para la administración local de agentes trombolíticos, así como trombectomía mecánica ${ }^{37}$.

El infarto esplénico es el resultado de la oclusión de una rama arterial esplénica, provocado principalmente por enfermedad tromboembólica o por enfermedades hematológicas infiltrativas. Clásicamente se visualizan como defectos de perfusión en cuña en el parénquima, aunque cuando son múltiples pueden fusionarse y perder dicha morfología. La clave es la extensión de la zona del parénquima anormal hasta la cápsula intacta (Figura 13). Los infartos agudos pueden complicarse con sobreinfección, hematomas subcapsulares o roturas esplénicas. Un infarto crónico pierde volumen con atrofia focal y puede calcificar ${ }^{38}$.

\section{Complicaciones relacionadas con el tratamiento anticoagulante}

Los anticoagulantes, como la heparina sódica y las HBPM, se usan actualmente para el tratamiento y la prevención de la enfermedad tromboembólica secundaria a la afectación por la COVID-19. Se estima que la hemorragia es una complicación a menudo grave de la terapia anticoagulante, en hasta el $4 \%$ de los pacientes tratados ${ }^{39}$. La hemorragia digestiva es una forma frecuente de complicación que habitualmente cede tras corregir el estado de coagulación. Otras formas frecuentes de complicaciones hemorrágicas graves son el hematoma de pared abdominal especialmente de los compartimentos musculares de la vaina del recto (Figura 14) o el músculo iliopsoas (Figura 15) con apertura al retroperitoneo (Figura 16), ambos son los que con mayor frecuencia requieren tratamiento percutáneo urgente. 

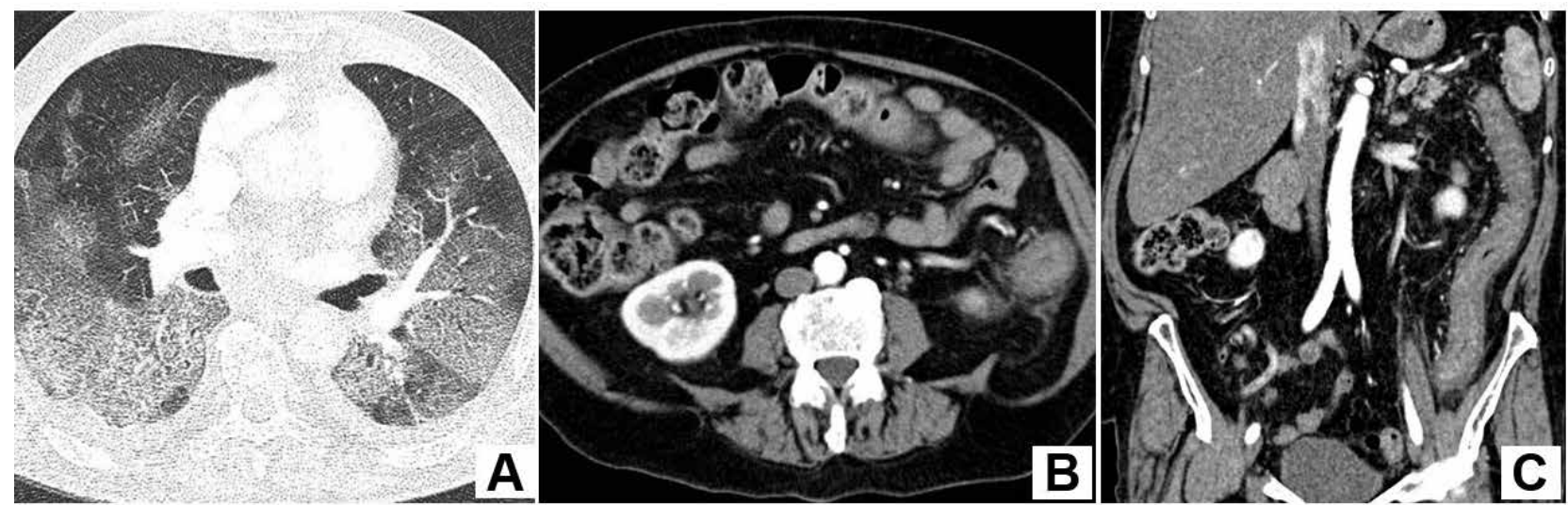

Figura 11: Varón de 70 años con afectación pulmonar COVID-19, presenta dolor abdominal agudo, rectorragia, aumento de PCR y Dímero-D. TC abdominal con contraste iv, ventana de pulmón en campos medios muestra afectación extensa y bilateral en vidrio deslustrado de predominio posterior. Corte a nivel de mesogastrio (b) y reconstrucción MPR coronal (c) muestra engrosamiento circunferencial de la pared del colon izquierdo con aumento de atenuación de la grasa adyacente sugestivo de colitis isquémica.

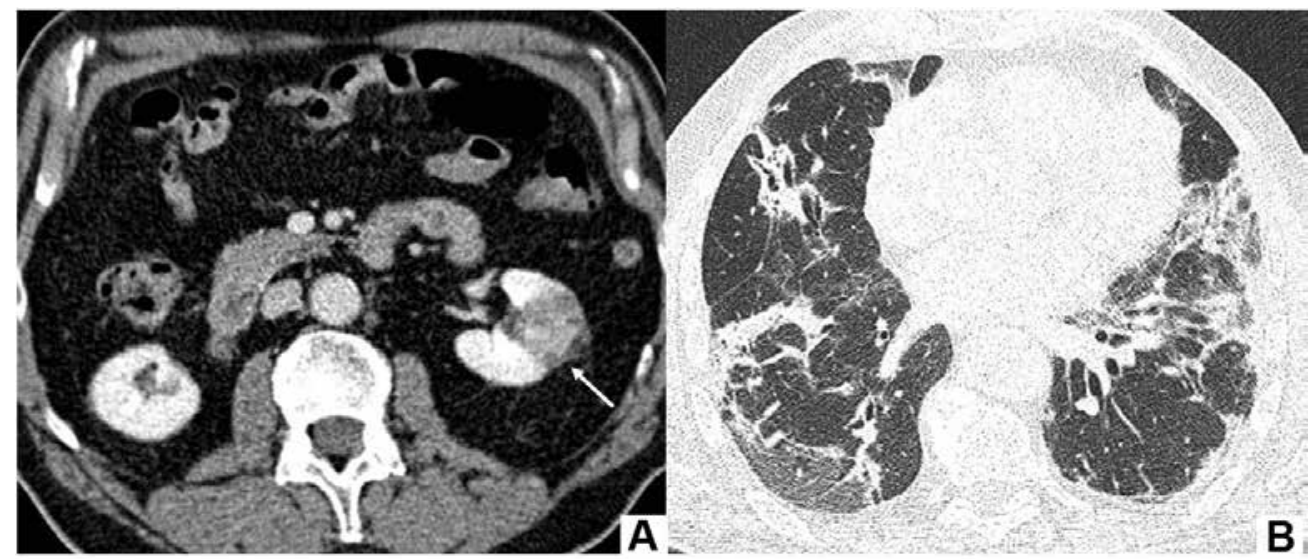

Figura 12: Varón de 78 años con afectación pulmonar por COVID-19, presenta dolor abdominal agudo, deterioro de función renal y elevación Dímero-D. TC abdominal con contraste iv (a). Infarto renal izquierdo (flecha). Ventana de pulmón a nivel de campos inferiores muestra patrón en empedrado, bandas subpleurales y bronquiectasias.

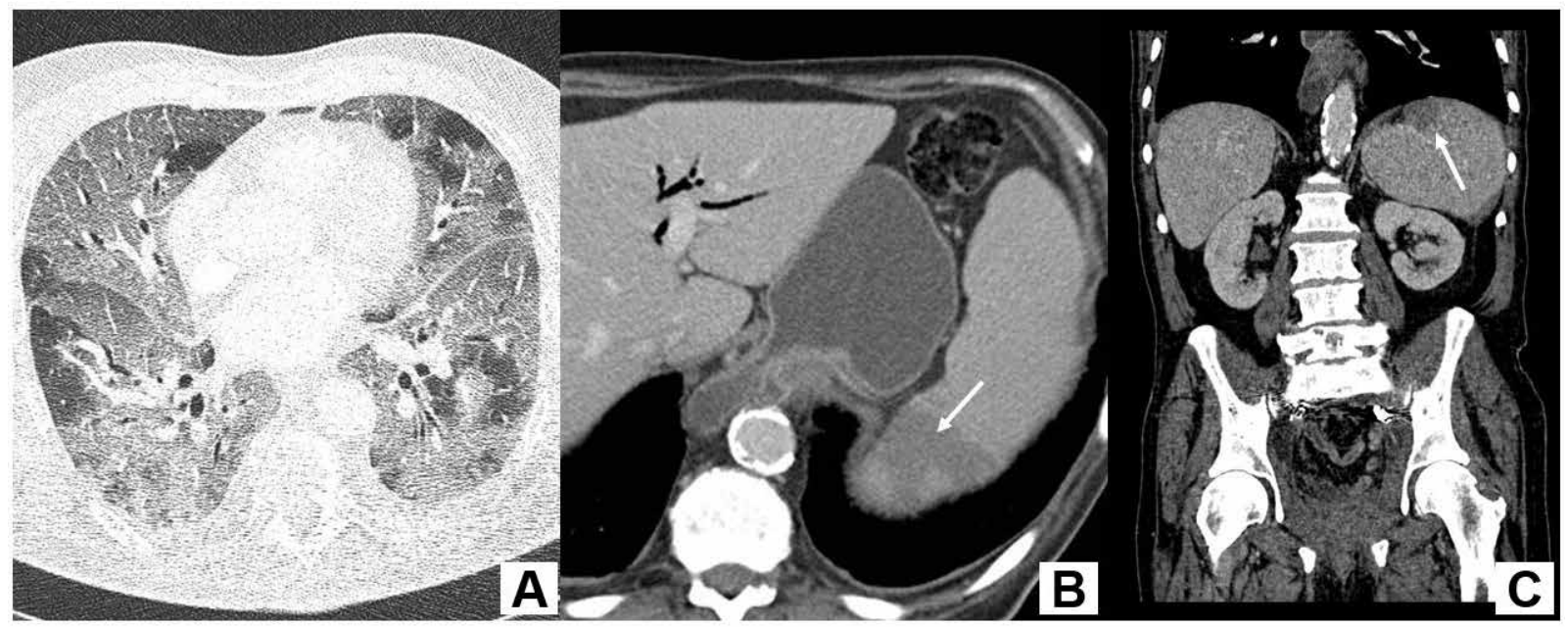

Figura 13: Varón de 70 años con afectación parenquimatosa COVID-19, presenta dolor abdominal agudo, fiebre y elevación Dímero-D. TC abdominal con contraste iv. Ventana de pulmón en campos medios muestra afectación extensa y bilateral en vidrio deslustrado. Corte con ventana de partes blandas en hemiabdomen superior (b) y reconstrucción MPR coronal (c) que demuestra hipodensidad triangular esplénica compatible con infarto (flecha). 


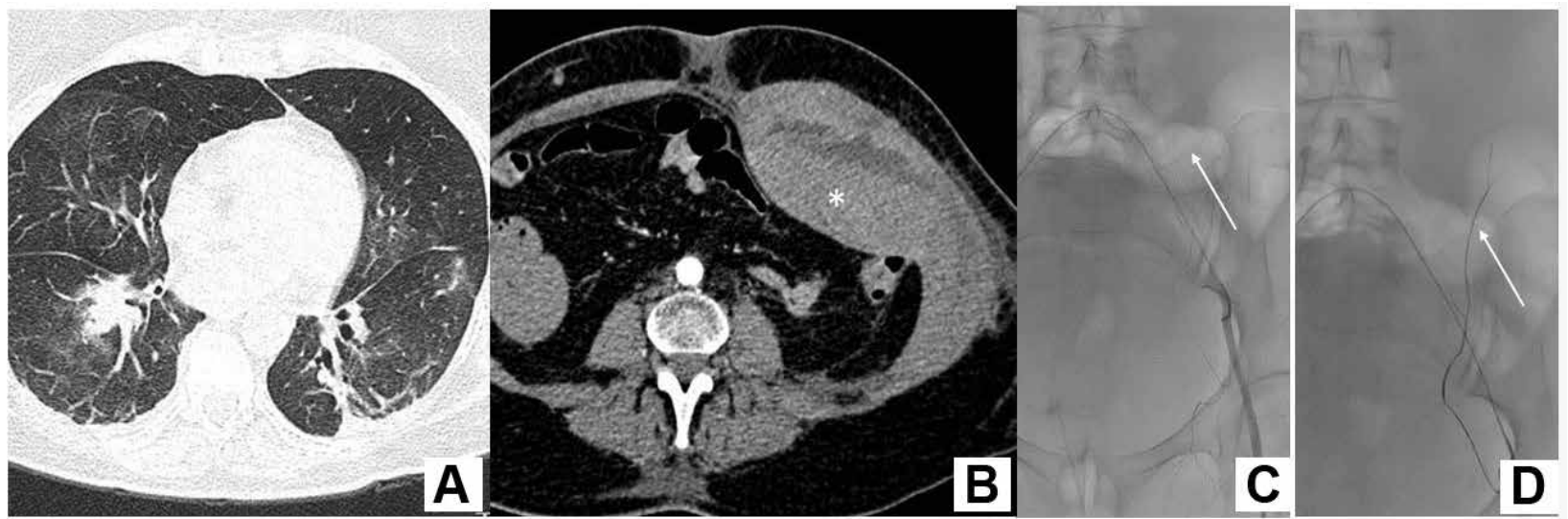

Figura 14: Mujer de 57 años con afectación pulmonar por COVID-19, TEP masivo y tratamiento con heparina, descenso brusco de la hemoglobina. TC abdominal con contraste iv, ventana de pulmón (a) muestra áreas parcheadas en vidrio deslustrado. En los cortes abdominales (b) hematoma en músculo recto anterior y oblicuos izquierdos del abdomen (*) con extensión a pelvis que depende de arteria epigástrica inferior izquierda. Angiografía pre y post embolización (c y d) de sangrado activo de arteria epigástrica inferior izquierda (Flechas).

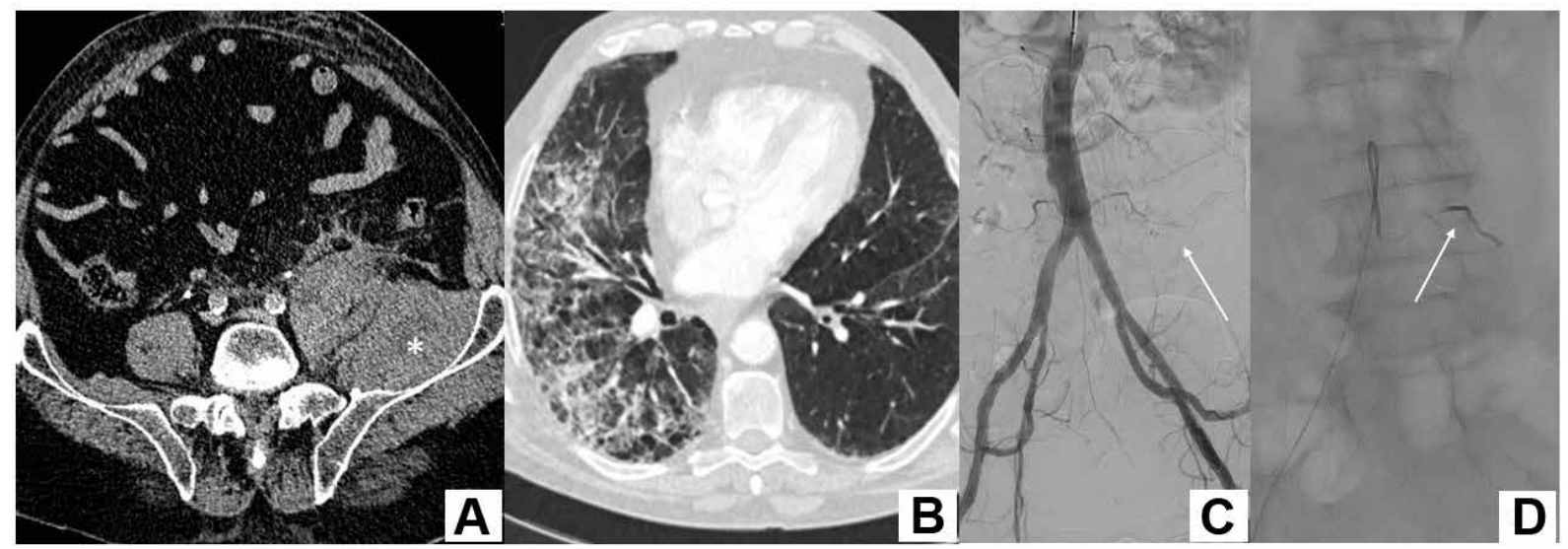

Figura 15: Varón de 71 años con afectación pulmonar COVID-19 y TEP unilateral derecho en tratamiento con HBPM a dosis anticoagulantes, presenta hipotensión y descenso de $3 \mathrm{mg} / \mathrm{dl}$ de hemoglobina. TC abdominal sin contraste iv. (a) Hematoma del músculo ilio-psoas $\left(^{*}\right)$ del lado izquierdo. Ventana de pulmón en campos medios (b) muestra patrón en empedrado en hemitórax derecho de predominio posterior. Arteriografía preembolización (c) de sangrado activo de arteria lumbar distal izquierda (Flechas), (d) post tratamiento con embolizante líquido.

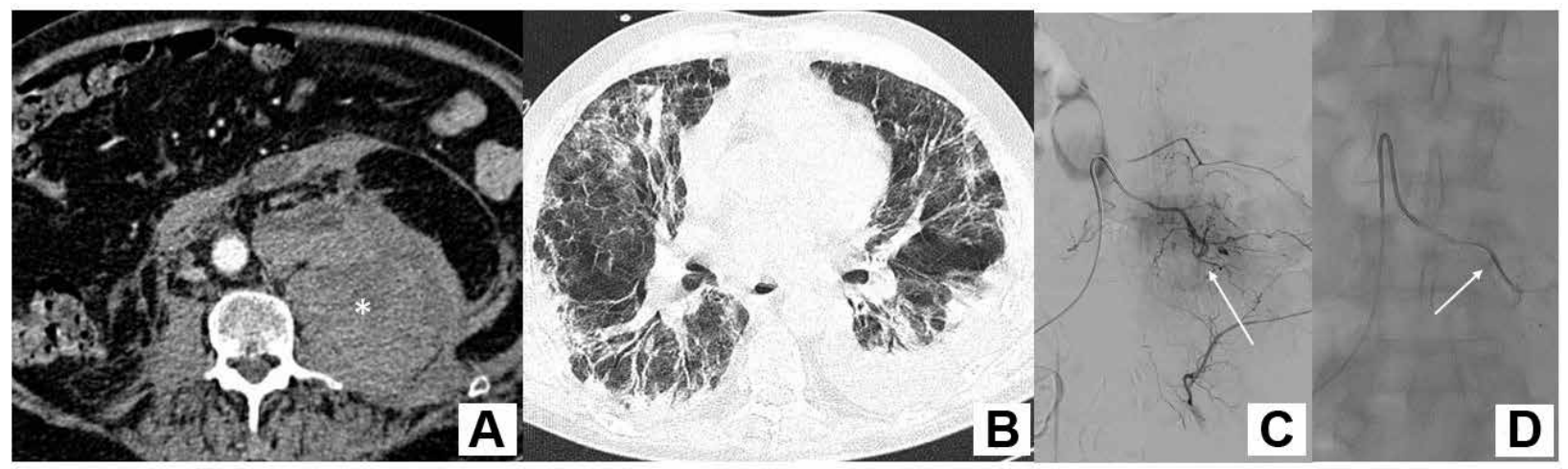

Figura 16: Mujer de 57 años con antecedente de FA, ingresada por afectación pulmonar por COVID-19 y tratamiento anticoagulante por TVP derecha, presenta hipotensión y descenso de $4 \mathrm{mg} / \mathrm{dl}$ de hemoglobina. TC abdominal con contraste iv (a). Hematoma extenso del psoas izquierdo $\left({ }^{*}\right)$ con aumento de atenuación de la grasa retroperitoneal. Ventana de pulmón en campos medios (b) donde se aprecia consolidación pulmonar de predominio periférico en ambos lóbulos inferiores y zonas parchadades de densidad en vidrio deslustrado. Arteriografía pre (a) y postembolización (b) de sangrado activo de arteria lumbar distal izquierda y arteria del iliopsoas (Flechas). 
Los factores de riesgo incluyen, además de la anticoagulación por el estado protrombótico inducido por la COVID-19, las comorbilidades específicas (enfermedad cardíaca grave, disfunción hepática, insuficiencia renal, hipertensión, enfermedad cerebrovascular y pacientes que reciben hemodiálisis a largo plazo), el uso de medicamentos concurrentes (principalmente agentes antiinflamatorios no esteroides y diuréticos), la duración del tratamiento, la intensidad del efecto anticoagulante y la edad del paciente ${ }^{40}$. El método diagnóstico de elección es la TC abdominal ya que, además de valorar el tamaño y localización del hematoma, constata la existencia de sangrado activo e identifica la arteria causante del sangrado. En caso de fallo del tratamiento conservador o de inestabilidad hemodinámica está indicado el tratamiento endovascular para la embolización del sangrado ${ }^{41}$. En los hematomas de la vaina de los rectos de localización baja, habitualmente la embolización de la arteria epigástrica inferior homolateral es suficiente para el control de la hemorragia (Figura 14d), mientras que los de ubicación alta a veces requieren de embolización distal de la arteria mamaria interna homolateral. En el caso de los hematomas retroperitoneales espontáneos, las arterias implicadas son las arterias lumbares y la arteria iliolumbar (Figuras 15d, 16d). Se aconseja el uso de materiales líquidos/ pegamentos cuyo efecto terapéutico es independiente del estado de la coagulación del paciente ${ }^{42}$.

\section{Enfermedades simuladoras}

Una amplia variedad de hallazgos en TC se ha descrito en la afectación pulmonar en la enfermedad COVID-19. Sin embargo, todos los estudios indican que la principal característica en la TC de pulmón es la presencia de opacidades en vidrio deslustrado, típicamente con una distribución periférica y subpleural, con afectación de múltiples lóbulos, particularmente los lóbulos inferiores ${ }^{1,43,44,45}$. El patrón en vidrio deslustrado representa tanto un proceso intersticial (engrosamiento intersticial) o alveolar (ocupación parcial de alveolos) y es una manifestación común de múltiples enfermedades pulmonares. En esta revisión describimos una serie de entidades con características en la TC pulmonar de opacidad en vidrio deslustrado que pueden simular la afectación del parénquima pulmonar en la COVID-19, tales como, edema pulmonar, hemorragia alveolar difusa, neumonía intersticial no específica (NINE), neumonitis por hipersensibilidad (NHS), neumonías atípicas, neumonitis rádica, metástasis, etc.

\section{Edema pulmonar}

El edema pulmonar es una causa muy común de opacidad en vidrio deslustrado difusa, pero se caracteriza por un predominio perihiliar y en regiones basales de los lóbulos inferiores, normalmente simétrica y con preservación de las porciones periféricas del pulmón, al contrario que la COVID-19. Se asocia con otros signos sugestivos, como engrosamiento septal que refleja los vasos linfáticos dilatados y engrosamiento de los septos interlobulillares (Figura 17). Un hallazgo común que apoya este diagnóstico es el derrame pleural asociado, frecuentemente bilateral ${ }^{46}$.
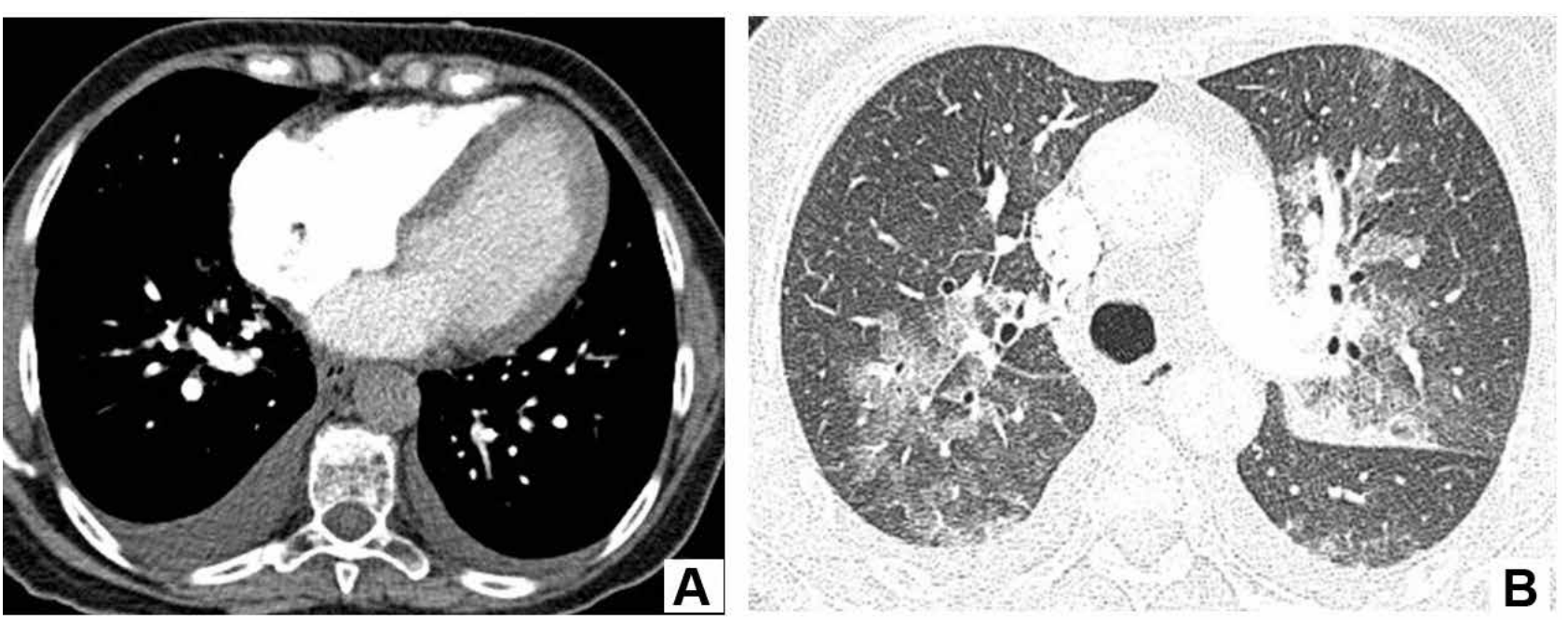

Figura 17: Varón de 81 años con múltiples factores de riesgo cardiovascular, consulta por tos y disnea progresiva de 2 semanas (sospecha de infección por SARS-CoV-2). AngioTAC de tórax, ventana de mediastino (a) y pulmón (b), muestra cardiomegalia, opacidad en vidrio deslustrado de distribución perihiliar, engrosamiento de cisuras y derrame pleural bilateral. 


\section{Hemorragia alveolar difusa}

La hemorragia alveolar difusa es una emergencia que se define como la presencia de sangre en los espacios alveolares. Ocurre por un daño en la microcirculación pulmonar (capilares, arteriolas y vénulas alveolares) y puede ser de origen pulmonar, por ejemplo, en la infección o de causa sistémica como ocurre en las vasculitis sistémicas. Clínicamente se puede manifestar como hemoptisis, disnea, tos de inicio agudo y anemización ${ }^{47,48}$. También se caracteriza por opacidades en vidrio deslustrado perihiliares y bilaterales de aparición súbita y que confluye progresivamente respetando los vértices y la periferia de los pulmones, sin existir un predominio subpleural (Figura 18). En la fase aguda puede ser indistinguible del edema pulmonar o de la infección pulmonar difusa ${ }^{49}$. A las 48-72 h del episodio se produce un patrón reticular y si no hay recurrencia del sangrado la imagen se puede normalizar en 1-2 semanas.

\section{Neumonía intersticial no específica (NINE)}

La neumonía intersticial no específica (NINE) es una enfermedad intersticial que afecta al parénquima pulmonar de etiología desconocida. EI pronóstico de esta entidad es mejor que el de otras enfermedades intersticiales como por ejemplo la neumonía intersticial usual (NIU) o la neumonía intersticial descamativa (NID). La TC de tórax es la prueba de imagen de elección para su estudio puesto que en la mayoría de los casos la radiografía de tórax es normal ${ }^{50}$. Se caracteriza por un patrón en vidrio deslustrado en localización periférica con afectación de los campos medios e inferiores (Figura 19). En ocasiones vemos una franca mejoría de los hallazgos en la imagen tras el tratamiento con esteroides. Si la enfermedad progresa se puede ver panalización o bronquiectasias por tracción ${ }^{50}$.

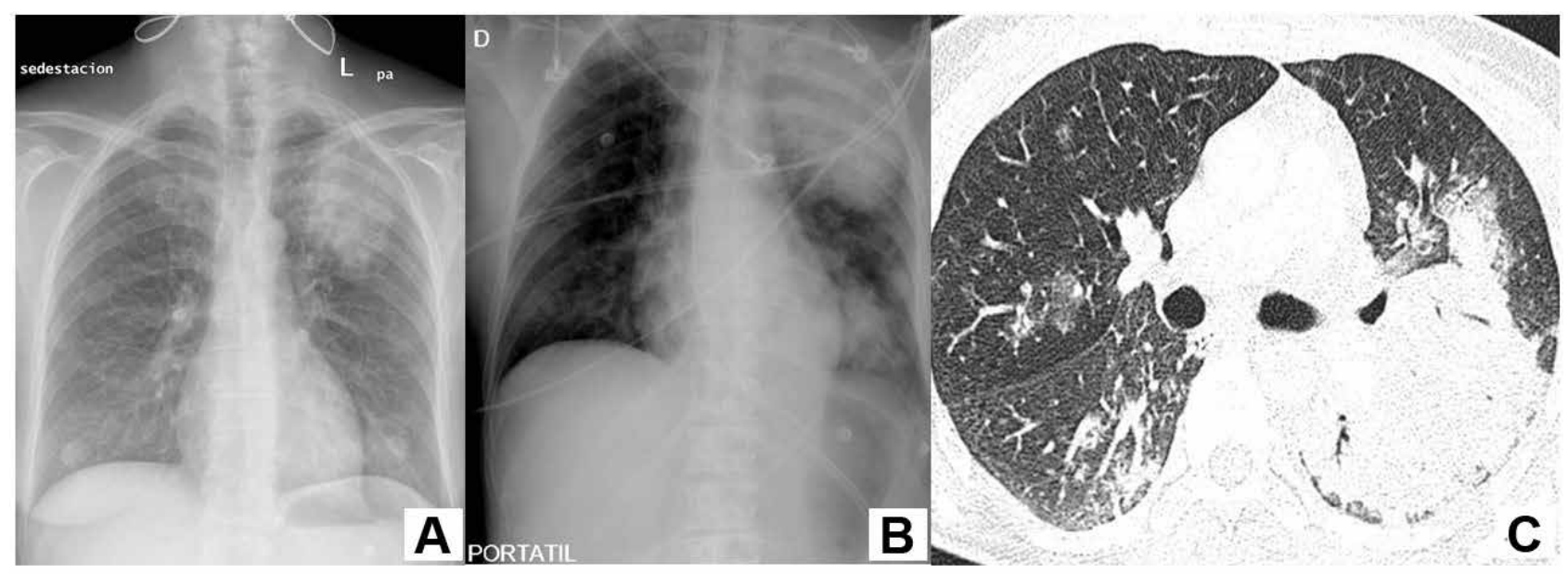

Figura 18: Mujer de 48 años con clínica de fiebre, disnea y hemoptisis leve, frotis de sangre periférico compatible con leucemia aguda. Radiografía de tórax PA al ingreso (a) muestra opacidades en LSI y retrocardiaca. Radioagrafía de tórax portatil control a la hora (b) muestra empeoramiento radiológico. TC de tórax, ventana de pulmón (c), muestra opacidades en vidrio deslustrado y consolidación. No se observa engrosamiento septal interlobular. Hallazgo compatible con hemorragia alveolar difusa aguda, dado el contexto clínico.
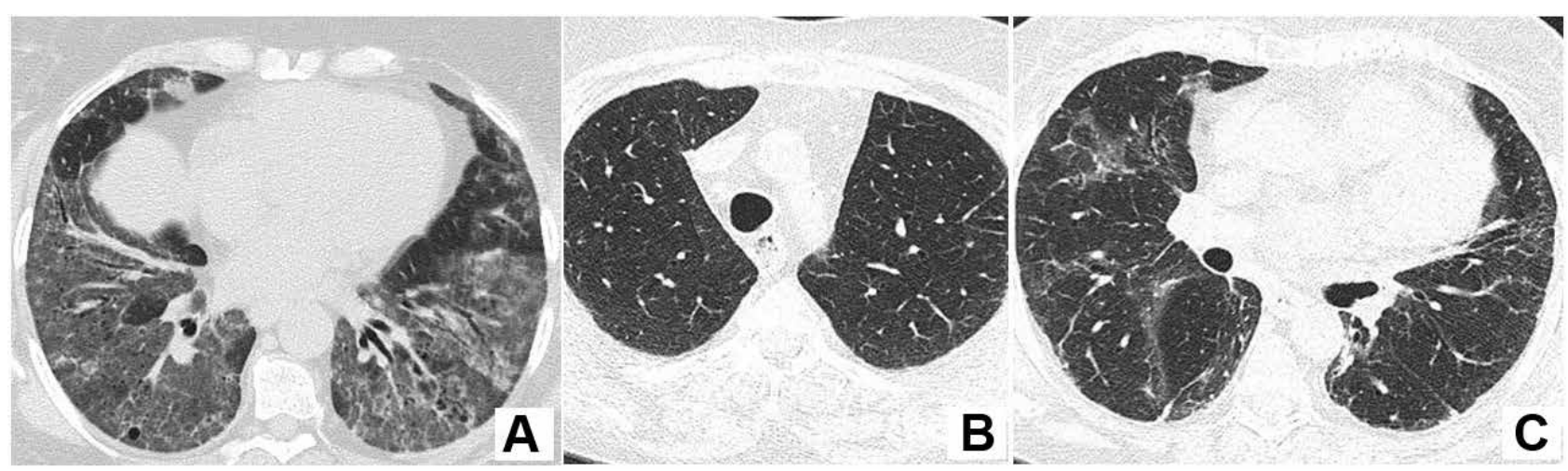

Figura 19: Mujer de con polimiosistis y diagnóstico de NINE en tratamiento con corticoides, consulta por tos sin disnea (sospecha de infección por SARS-CoV-2). TC de pulmón previo de diciembre 2018, sin contraste iv. Ventana de pulmón en campos inferiores (a) Patrón reticular fino y vidrio deslustrado con distribución basal sin componente fibrótico. TC de pulmón al ingreso a nivel de campos superiores (b) e inferiores (c), discreto patrón reticular probablemente residual y no concluyente para COVID-19, con preservación de campos superiores. 


\section{Neumonitis por hipersensibilidad}

La neumonitis por hipersensibilidad (NHS), también conocida como alveolitis alérgica extrínseca, es una enfermedad inflamatoria granulomatosa de los pulmones causada por la inhalación de partículas o humos orgánicos antigénicos ${ }^{51}$. En el caso del pulmón del cuidador de aves, son partículas que suelen encontrarse en el epitelio, el polvo que cubre las plumas o las heces de las aves ${ }^{52}$. La enfermedad puede presentarse como una enfermedad aguda, subaguda o crónica. Los episodios de NHS aguda y subaguda generalmente se resuelven después del cese de la exposición al antígeno una vez establecido el diagnostico; los corticoides se utilizan en fases tempranas para acelerar la curación o en fases severas o evolucionadas que pueden ser progresivas e irreversibles ${ }^{51}$. En TC de tórax la combinación de un patrón de mosaico con áreas de vidrio esmerilado y nódulos centrolobulillares es altamente sugestivo del diagnóstico (Figura 20) ${ }^{53}$. Una cuidadosa historia ambiental y ocupacional y el establecimiento de la exposición a un antígeno incitante conocido son factores clave para hacer el diagnóstico de NHS.

\section{Neumonías atípicas}

El grupo de las neumonías atípicas está constituido por las neumonías producidas por virus, Pneumocystis jirovecii y bacterias atípicas (Legionella pneumophila, Mycoplasma pneumoniae y Chlamydia pneumoniae). En la TC torácica las neumonías atípicas producen alteraciones pulmonares bilaterales, extensas y a menudo simétricas con patrón de vidrio deslustrado ${ }^{54}$.

La neumonía por Pneumocystis jirovecii era la infección más común en pacientes con síndrome de inmunodeficiencia adquirida (SIDA), pero ha sido sustituida por la infección bacteriana desde la instau- ración de su profilaxis. Los pacientes no-VIH típicamente presentan una clínica más aguda con fiebre e hipoxemia, mientras los pacientes $\mathrm{VIH}$ frecuentemente manifiestan un pródromo de 2-3 semanas con fiebre de bajo grado, pérdida de peso, disnea y malestar. El hallazgo más común en la TC son opacidades en vidrio deslustrado de distribución simétrica, habiendo sido descrito un predominio por los lóbulos superiores (Figura 21). Este hallazgo puede estar asociado a otras alteraciones incluidas consolidaciones, engrosamiento septal y quistes de pared fina que pueden dar lugar a neumotórax espontáneo ${ }^{55}$. El diagnóstico definitivo requiere la identificación del organismo de muestras respiratorias con tinción de anticuerpos fluorescentes o reacción en cadena de la polimerasa $(\mathrm{PCR})^{56}$.

\section{Neumonitis Post-Actínica}

El daño pulmonar inducido por la radioterapia se manifiesta radiológicamente de forma diversa, dependiendo del tiempo transcurrido desde la finalización del tratamiento. En las fases precoces, entre 1 y 3 meses tras la radioterapia; en las fases tardías o crónicas, desarrolladas posteriormente y con estabilización sobre los 12-15 meses, los hallazgos se denominan fibrosis rádica. Ocurre en $<1 \%$ de los casos y es dosis dependiente siendo constante a partir de los $40 \mathrm{~Gy}^{57}$. Se manifiesta como tos y disnea a los 3 meses de haber recibido la radioterapia, aunque el tiempo de aparición es variable. La TC no solo es más capaz de delinear los cambios parenquimatosos, sino que a menudo demuestra cambios localizados en el campo irradiado, lo que facilita el diagnóstico, Los dos hallazgos más comunes son las opacidades en vidrio deslustrado y/ o la consolidación del espacio aéreo (Figura 22) ${ }^{58}$.
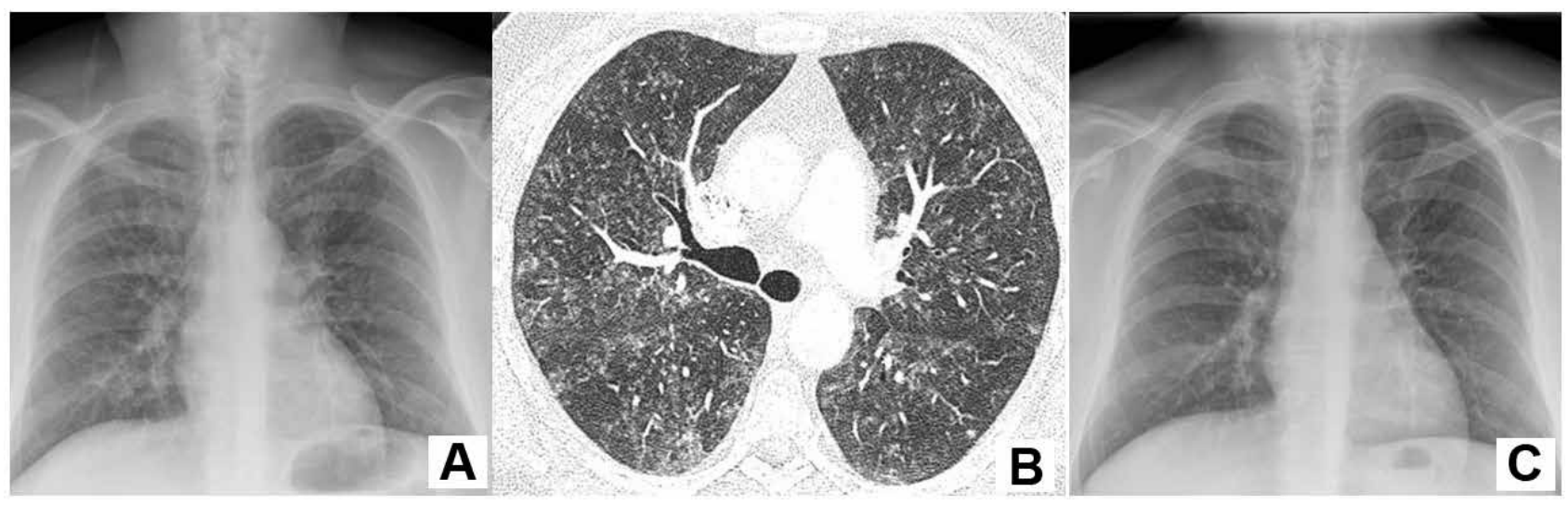

Figura 20: Varón de 47 años con disnea de moderados esfuerzos, 2 semanas, (sospecha de infección por SARS-COV-2). Antecedente epidemiológico de contacto con pájaros. Radiografía de tórax AP (a) muestra opacidades difusas en campos superiores y medios. TC de tórax axial (b) Opacidades en vidrio deslustrado asociado a nódulos centrolobulillares en vidrio deslustrado de predominio en campos superiores. Radiografía de tórax AP (c) Mejoría radiológica del patrón pulmonar tras administración de corticoides. Hallazgo compatible con NHS. 

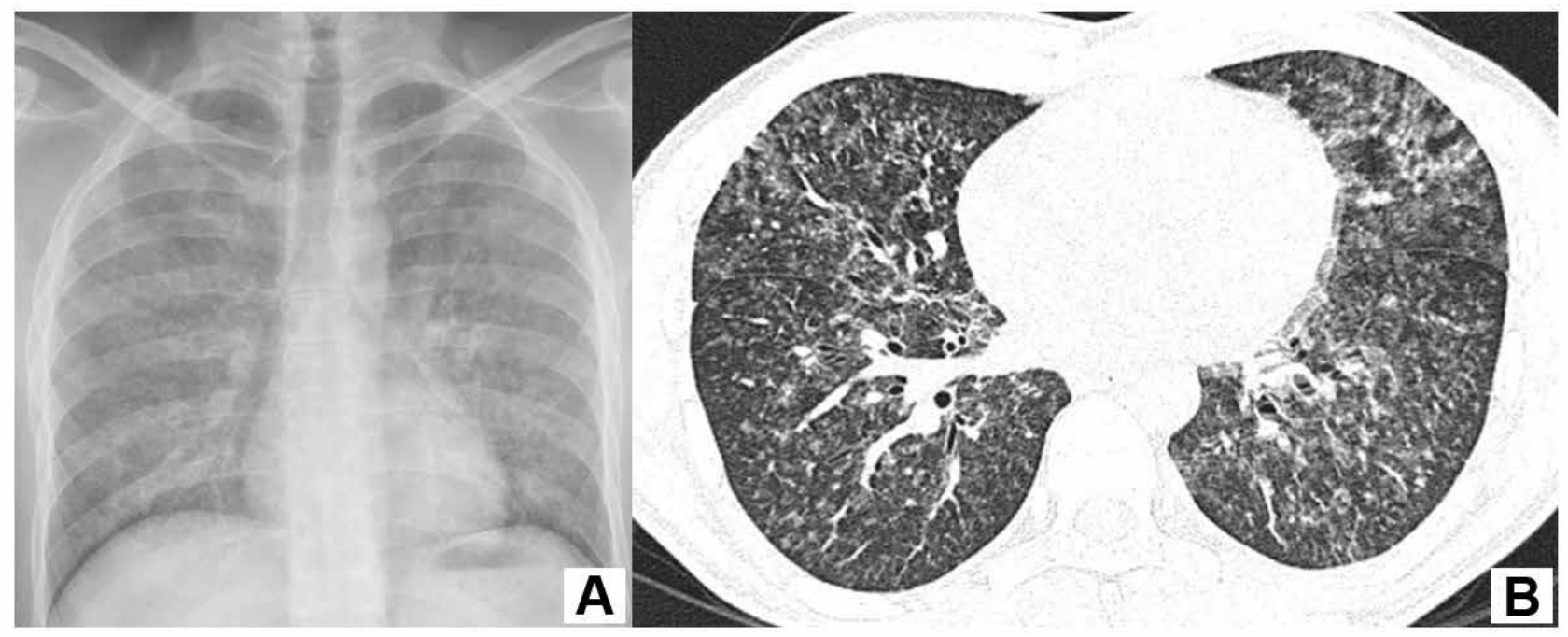

Figura 21: Varón de 32 años con disnea de moderados esfuerzos de 3 semanas, (sospecha de infección por SARSCOV-2). Antecedente epidemiológico de VIH con inmunosupresión severa. Radiografía de tórax AP (a) muestra opacidades pulmonares difusas. TC de tórax axial (b) Opacidades en vidrio deslustrado asociado a nódulos centrolobulillares en vidrio deslustrado de distribución simétrica. PCR-coronavirus (negativo) y PCR-Pneumocystis jirovecii (positiva).

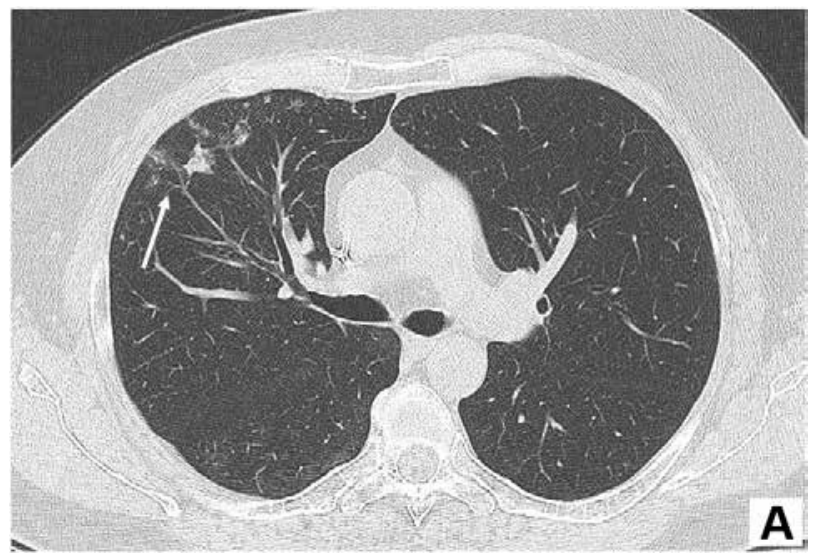

Figura 22: Mujer de 57 años con antecedente de carcinoma ductal infiltrante de mama derecha. En la 8 a semanas tras la finalización de la radioterapia, se presenta con clínica de disnea y tos de 2 semanas (sospecha de infección por SARS-CoV-2). TC de tórax, ventana de pulmón (a) muestra opacidades en vidrio deslustrado en el lóbulo superior derecho anterior (Flecha).

\section{Metástasis pulmonares}

Los hallazgos radiológicos típicos de las metástasis pulmonares consisten en múltiples nódulos de tamaño variable y engrosamiento difuso del intersticio (Figura 23). La opacidad en vidrio deslustrado alrededor de la masa (signo del halo en la TC de tórax) puede ser visto cuando la fragilidad del tejido neovascular conduce a la rotura de vasos, como en las metástasis de coriocarcinoma y angiosarcoma, así como en el crecimiento del tumor a lo largo de las paredes alveolares como en adenocarcinomas de tumores del tracto gastrointestinal ${ }^{59}$.

\section{Linfangitis carcinomatosa}

La linfangitis carcinomatosa constituye un patrón de diseminación tumoral a través de los vasos linfáticos pulmonares, siendo factor de mal pronóstico en cuanto a la respuesta a la quimioterapia y a la supervivencia. El $80 \%$ de los casos es causada por adenocarcinomas, siendo los tumores más comunes pulmón, mama, colon y estómago ${ }^{60}$. Los hallazgos en la TC de tórax incluyen engrosamiento liso o nodular de los septos interlobulares y el engrosamiento del intersticio peribroncovascular y subpleural, así como adenopatías mediastínicas e hiliares, y derrame pleural (Figura 24). Puede presentarse tanto de forma uni como bilateral ${ }^{61}$.

\section{Nódulos pulmonares calcificados}

Los nódulos pulmonares múltiples calcificados ocurren en una amplia variedad de enfermedades y en las radiografías de tórax pueden simular opacidades parcheadas pulmonares localizadas. Son múltiples los procesos que condicionan la aparición de nódulos pulmonares calcificados (Figura 25). Así, aparecen en las fases reparativas de procesos inflamatorios (TBC, varicela), tumores benignos y malignos (hamartomas, hemangioendotelioma epitelioide, metástasis), las enfermedades inhalatorias (neumoconiosis de los trabajadores del carbón y silicosis), enfermedades metabólicas (insuficiencia renal, hipercalcemia) y procesos de origen desconocido (microlitiasis alveolar) ${ }^{62}$. 

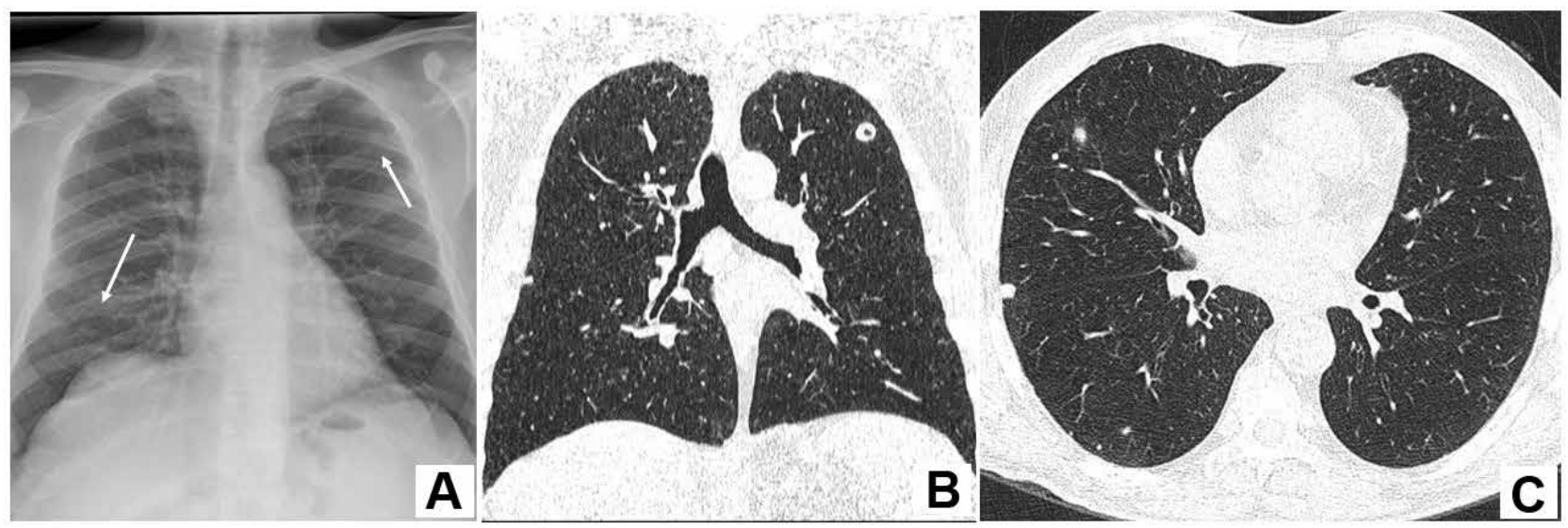

Figura 23: Varón de 72 años con antecedente de carcinoma renal en tratamiento quimioterápico con tos y disnea de 3 días (sospecha de infección por SARS-COV-2). Radiografía de tórax AP (a) muestra tenues opacidades en LII y LSI (flechas). $T C$ de tórax, ventana de pulmón y reconstrucción MPR en plano coronal (d) y axial(d), muestra múltiples nódulos en ambos hemitórax sugerentes de metástasis.
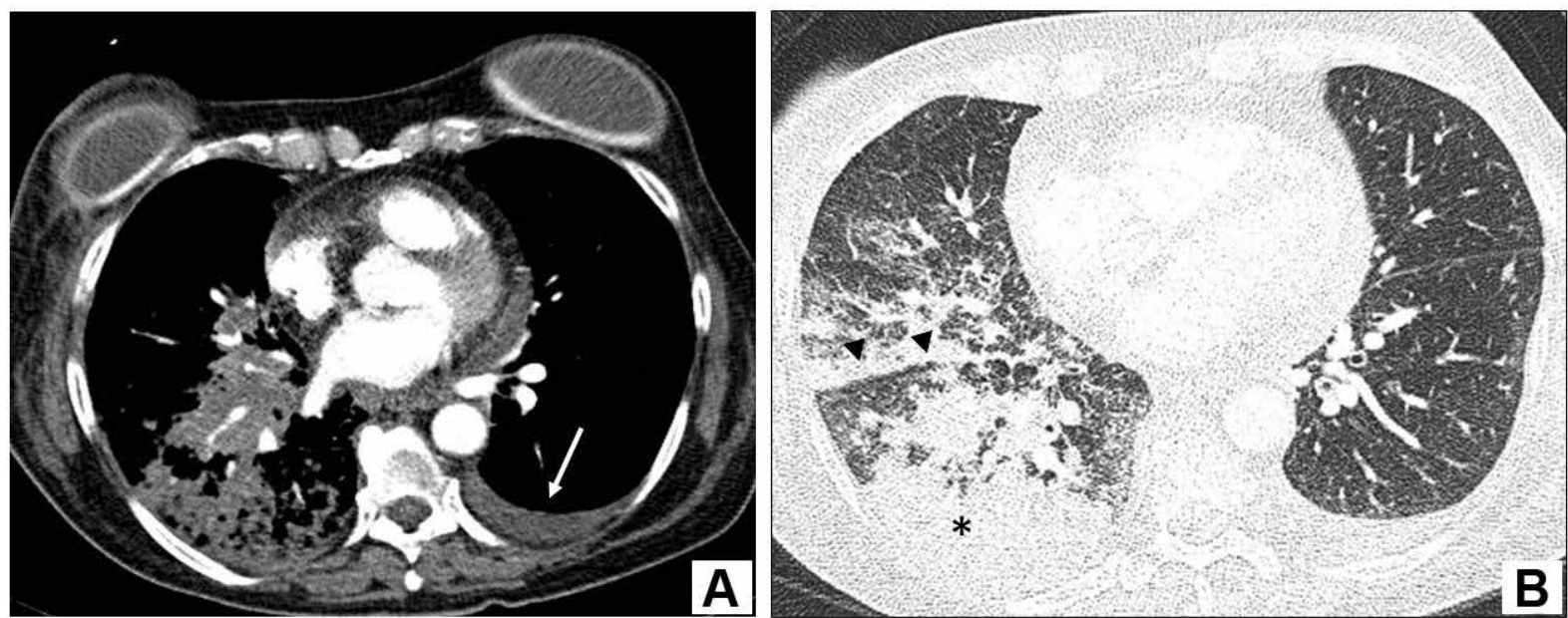

Figura 24: Mujer de 57 años con antecedente de carcinoma ductal infiltrante de mama derecha y linfangitis carcinomatosa. AngioTAC de tórax, ventana de mediastino (a) y ventana de pulmón (b) muestra engrosamiento nodular cisural (punta de flecha) y de septos interlobulares, opacidades en vidrio deslustrado u consolidación ( $\left(^{*}\right)$ de distribución unilateral derecha. Se observa también derrame pleural bilateral (Flecha).
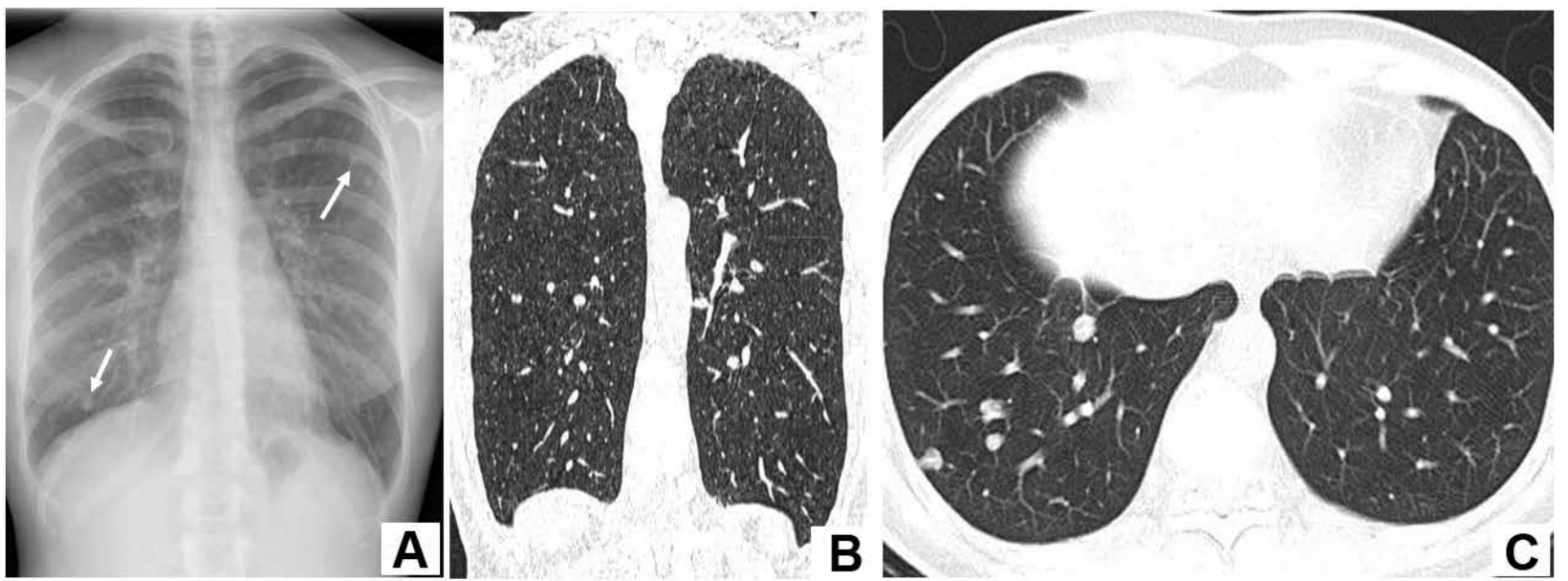

Figura 25: Mujer de 30 años sin antecedentes de relevancia con clínica de una semana de tos y malestar general (sospecha de infección por SARS-COV-2). Radiografía de tórax AP (a) muestra múltiples nódulos pulmonares subcentimétricos en ambos hemitórax de predominio en lóbulos superiores. TC de tórax reconstrucción MPR coronal (b) y axial (c) ventana de pulmón confirma estos hallazgos. 


\section{Conclusión}

La imagen radiológica juega un papel muy relevante en el diagnóstico y seguimiento de los pacientes con la enfermedad COVID-19. Los hallazgos más frecuentes en las radiografías de tórax y en la TC de tórax incluyen opacidades en vidrio deslustrado bilaterales multifocales y consolidaciones irregulares de distribución predominantemente periférica. Además del compromiso pulmonar es relevante identificar otros hallazgos asociados, tales como la afectación extraparenquimatosa pulmonar, las complicaciones secundarias al estado protrombótico dada la alta incidencia de fenómenos trombóticos y embólicos, también las complicaciones hemorrágicas por tratamiento anticoagulante. Así mismo, se debe incluir en el diagnostico diferencial entidades que debuten con patrón pulmonar en opacidades en vidrio deslustrado. Todas estas características pueden ayudar a un diagnóstico rápido, guiar la toma de decisiones clínicas y controlar la progresión de la enfermedad COVID-19. Se debe prestar especial atención al papel de los radiólogos en la lucha contra esta nueva enfermedad infecciosa.

\section{Referencias}

1. Zhu N, Zhang D, Wang W, Li X, Yang B, Song J, et al. A Novel Coronavirus from Patients with Pneumonia in China 2019. N Engl J Med. 2020 febrero 20; 382(8): 727-733.

2. WHO Team. Nuevo coronavirus 2019 (citado 28 de mayo de 2020). Disponible en: https://www.who.int/es/ emergencies/diseases/novel-coronavirus-2019

3. Ministerio de Sanidad. Consumo y Bienestar SocialProfessionals-Situación actual Coronavirus (citado 21 de mayo de 2020). Disponible en: https://www.mscbs. gob.es/en/profesionales/saludPublica/ccayes/alertasActual/nCov-China/situacionActual.htm

4. Chung M, Bernheim A, Mei X, Zhang N, Huang M, Zeng $\mathrm{X}$, et al. CT Imaging Features of 2019 Novel Coronavirus (2019-nCoV). Radiology. 2020 febrero 4; 295(1): 202-207.

5. Lupia T, Scabini S, Mornese Pinna S, Di Perri G, De Rosa FG, Corcione S. 2019 novel coronavirus (2019$\mathrm{nCoV}$ ) outbreak: A new challenge. Journal of Global Antimicrobial Resistance. 2020 junio 1; 21: 22-27.

6. Ye Z, Zhang $Y$, Wang $Y$, Huang Z, Song B. Chest CT manifestations of new coronavirus disease 2019 (COVID-19): a pictorial review. (citado 21 de mayo de 2020). Eur Radiol. 2020 marzo 19; 30(8): 4381-4389. Disponible en: https://doi.org/10.1007/s00330-020-06801-0

7. Zhou C, Gao C, Xie Y, Xu M. COVID-19 with spontaneous pneumomediastinum. Lancet Infect Dis. 2020 abril; 20(4): 510.

8. Meireles J, Neves S, Castro A, França M. Spontaneous pneumomediastinum revisited. Respiratory Medicine CME. 2011 enero 1; 4(4): 181-183.

9. Murayama S, Gibo S. Spontaneous pneumomediastinum and Macklin effect: Overview and appearance on computed tomography. World J Radiol. 2014 noviembre 28; 6(11): 850-854.
10. Meng L, Qiu H, Wan L, Ai Y, Xue Z, Guo Q, et al. Intubation and Ventilation amid the COVID-19 OutbreakWuhan's Experience. Anesthesiology. 2020 junio 1; 132(6): 1317-1332.

11. Wang W, Gao R, Zheng Y, Jiang L. COVID-19 with spontaneous pneumothorax,pneumomediastinum and subcutaneous emphysema. J Travel Med. 2020 abril 25; 27(5): taaa062.

12. Rohailla S, Ahmed N, Gough K. SARS-CoV-2 infection associated with spontaneous pneumothorax. CMAJ. 2020 abril 21; 192(19): E510.

13. Bintcliffe $O$, Maskell N. Spontaneous pneumothorax. BMJ (citado 21 de mayo de 2020). 2014 mayo 8; 348. Disponible en: https://www.bmj.com/content/348/bmj. g2928

14. Tang N, Li D, Wang X, Sun Z. Abnormal coagulation parameters are associated with poor prognosis in patients with novel coronavirus pneumonia. J Thromb Haemost. 2020; 18(4): 844-847.

15. Margetic S. Inflammation and haemostasis. Biochem Med (Zagreb). 2012 febrero 15; 22(1): 49-62.

16. Grillet F, Behr J, Calame P, Aubry S, Delabrousse E. Acute Pulmonary Embolism Associated with COVID-19 Pneumonia Detected by Pulmonary CT Angiography. Radiology. 2020 abril 23; 201544.

17. Franco-López Á, Poveda JE, Gilabert NV. Tromboembolismo Pulmonar en los pacientes con COVID-19. Angiografía con tomografía computarizada: resultados preliminares (citado 22 de mayo de 2020). JNNPR. 2019; 5(6): 569-668. Disponible en: https://revistas. proeditio.com/jonnpr/article/view/3689

18. Revel M-P, Parkar AP, Prosch H, Silva M, Sverzellati $\mathrm{N}$, Gleeson F, et al. COVID-19 patients and the radiology department-advice from the European Society of Radiology (ESR) and the European Society of Thoracic Imaging (ESTI). Eur Radiol. 2020 abril 20; 30: 4903-4909.

19. Chaaya G, Vishnubhotla P. Pulmonary Vein Thrombosis: A Recent Systematic Review (citado 22 de mayo de 2020). Cureus. 2017; 9(1): e993. Disponible en: https:// www.ncbi.nlm.nih.gov/pmc/articles/PMC5323025/

20. Barreiro TJ, Kollipara VK, Gemmel DJ. Idiopathic pulmonary vein thrombosis? (citado 22 de mayo de 2020). Respirol Case Rep. 2017 octubre 24; 6(1): e00277. Disponible en: https://www.ncbi.nlm.nih.gov/ pmc/articles/PMC5757585/

21. Kim SD, Hwang JK, Lee JH, Cho HJ, Sung GY, Moon IS, et al. Free Floating Thrombus of the Aorta: An Unusual Cause of Peripheral Embolization. Journal of the Korean Surgical Society. 2011 marzo 1; 80(3): 204-211.

22. Weiss S, BühImann R, von Allmen RS, Makaloski V, Carrel TP, Schmidli J, et al. Management of floating thrombus in the aortic arch. J Thorac Cardiovasc Surg. 2016; 152(3): 810-817.

23. Yang $S$, Yu J, Zeng W, Yang L, Teng L, Cui $Y$, et al. Aortic floating thrombus detected by computed tomography angiography incidentally: Five cases and a literature review. J Thorac Cardiovasc Surg. 2017; 153(4): 791-803.

24. Bo H, Li Y, Liu G, Ma Y, Li Z, Cao J, et al. Assessing the Risk for Development of Deep Vein Thrombosis among Chinese Patients using the 2010 Caprini Risk 
Assessment Model: A Prospective Multicenter Study. J Atheroscler Thromb. 2019 diciembre 17; 27(8): 801808.

25. Cook DJ, Crowther MA, Meade MO, Douketis J, VTE in the ICU Workshop Participants. Prevalence, incidence, and risk factors for venous thromboembolism in medical-surgical intensive care unit patients. J Crit Care. 2005 diciembre; 20(4): 309-313.

26. Marone EM, Rinaldi LF. Upsurge of deep venous thrombosis in patients affected by COVID-19: Preliminary data and possible explanations. J Vasc Surg Venous Lymphat Disord. 2020 abril 17; 8(4): 694-695.

27. Smeeth L, Cook C, Thomas S, Hall AJ, Hubbard R, Vallance P. Risk of deep vein thrombosis and pulmonary embolism after acute infection in a community setting. Lancet. 2006 abril 1; 367(9516): 1075-1079.

28. Rosendaal FR. Venous thrombosis: a multicausal disease. Lancet. 1999 abril 3; 353(9159): 1167-1173.

29. Mao L, Jin H, Wang M, Hu Y, Chen S, He Q, et al. Neurologic Manifestations of Hospitalized Patients With Coronavirus Disease 2019 in Wuhan, China. JAMA Neurol. 2020 abril 10; 77(6): 1-9.

30. Zhang Y, Xiao M, Zhang S, Xia P, Cao W, Jiang W, et al. Coagulopathy and Antiphospholipid Antibodies in Patients with Covid-19. N Engl J Med. 23 de 2020; 382(17): e38.

31. Thachil J, Tang N, Gando S, Falanga A, Cattaneo M, Levi $\mathrm{M}$, et al. ISTH interim guidance on recognition and management of coagulopathy in COVID-19. J Thromb Haemost. 2020; 18(5): 1023-1026.

32. Avula A, Nalleballe K, Narula N, Sapozhnikov S, Dandu V, Toom S, et al. COVID-19 presenting as stroke. Brain Behav Immun. 2020 abril 28; 87: 115-119.

33. Mei H, Hu Y. Characteristics, causes, diagnosis and treatment of coagulation dysfunction in patients with COVID-19. Zhonghua Xue Ye Xue Za Zhi. 14 de 2020; 41(3): 185-191.

34. Vulliamy $P$, Jacob S, Davenport RA. Acute aorto-iliac and mesenteric arterial thromboses as presenting features of COVID-19. Br J Haematol. 2020 abril 30; 189(6): 1053-1054.

35. Lee SS, Park SH. Computed tomography evaluation of gastrointestinal bleeding and acute mesenteric ischemia. Radiol Clin North Am. 2013 enero; 51(1): 29-43.

36. Mönkemüller K, Fry L, Rickes S. COVID-19, coronavirus, SARS-CoV-2 and the small bowel. Rev Esp Enferm Dig. 2020 mayo; 112(5): 383-388.

37. Decoste R, Himmelman JG, Grantmyre J. Acute renal infarct without apparent cause: A case report and review of the literature. Can Urol Assoc J. 2015 abril; 9(3-4): E237-239.

38. Freeman JL, Jafri SZ, Roberts JL, Mezwa DG, Shirkhoda A. CT of congenital and acquired abnormalities of the spleen. Radiographics. 1993 mayo; 13(3): 597-610.

39. Landefeld CS, Beyth RJ. Anticoagulant-related bleeding: clinical epidemiology, prediction, and prevention. Am J Med. 1993 septiembre; 95(3): 315-328.

40. Nazarian LN, Lev-Toaff AS, Spettell CM, Wechsler RJ. CT assessment of abdominal hemorrhage in coagulopathic patients: impact on clinical management. Abdom Imaging. 1999 junio; 24(3): 246-249.

41. Donaldson J, Knowles CH, Clark SK, Renfrew I, Lobo MD. Rectus sheath haematoma associated with low molecular weight heparin: a case series. Ann R Coll Surg Engl. 2007 abril; 89(3): 309-312.

42. Pathi R, Voyvodic F, Thompson WR. Spontaneous extraperitoneal haemorrhage: computed tomography diagnosis and treatment by selective arterial embolization. Australas Radiol. junio 2004; 48(2): 123-128.

43. Hani C, Trieu NH, Saab I, Dangeard S, Bennani S, Chassagnon G, et al. COVID-19 pneumonia: A review of typical CT findings and differential diagnosis. Diagnostic and Interventional Imaging. 2020 mayo 1; 101(5): 263-268.

44. Wang Y, Dong C, Hu Y, Li C, Ren Q, Zhang X, et al. Temporal Changes of CT Findings in 90 Patients with COVID-19 Pneumonia: A Longitudinal Study. Radiology. 2020 marzo 19; 200843.

45. Cheng Z, Lu Y, Cao Q, Qin L, Pan Z, Yan F, et al. Clinical Features and Chest CT Manifestations of Coronavirus Disease 2019 (COVID-19) in a Single-Center Study in Shanghai, China. AJR Am J Roentgenol. 2020 marzo 14; 1-6.

46. Chen C, Zhou Y, Wang DW. SARS-CoV-2: a potential novel etiology of fulminant myocarditis. Herz. 2020; 45(3): 230-232.

47. Buendía-Roldán I, Navarro C, Rojas-Serrano J. Diffuse alveolar hemorrhage: Causes and outcomes in a referral center. Reumatol Clin. 2010 agosto; 6(4): 196-198.

48. Gómez-Román JJ. Hemorragias alveolares difusas pulmonares. Arch Bronconeumol. 2008 agosto 1; 44(8): 428-36.

49. Cordier J-F, Cottin V. Alveolar hemorrhage in vasculitis: primary and secondary. Semin Respir Crit Care Med. 2011 junio; 32(3): 310-321.

50. Giménez Palleiro A, Franquet T. Patrones radiológicos en la enfermedad pulmonar intersticial. Semin Fund Esp Reumatol. 2013 octubre 1; 14(4): 97-105.

51. Mohr LC. Hypersensitivity pneumonitis. Curr Opin Pulm Med. 2004 septiembre; 10(5): 401-411.

52. Morell F, Roger À, Reyes L, Cruz MJ, Murio C, Muñoz X. Bird Fancier's Lung: A Series of 86 Patients. Medicine. 2008 marzo; 87(2): 110-130.

53. Glazer CS, Rose CS, Lynch DA. Clinical and radiologic manifestations of hypersensitivity pneumonitis. J Thorac Imaging. 2002 octubre; 17(4): 261-272.

54. Miller WT, Shah RM. Isolated diffuse ground-glass opacity in thoracic CT: causes and clinical presentations. AJR Am J Roentgenol. febrero de 2005; 184(2): 613-622.

55. Tian XL, Peng M, Wang HP, Cai BQ, Xu WB, Zhu YJ, et al. The differential diagnosis for novel coronavirus pneumonia and similar lung diseases in general hospitals. Zhonghua Jie He He Hu Xi Za Zhi. 2020 marzo 10; 43(0): E035.

56. Shelhamer JH, Gill VJ, Quinn TC, Crawford SW, Kovacs JA, Masur $\mathrm{H}$, et al. The laboratory evaluation of opportunistic pulmonary infections. Ann Intern Med. 1996 marzo 15; 124(6): 585-599.

57. Mesurolle B, Qanadli SD, Merad M, Mignon F, Baldeyrou $P$, Tardivon A, et al. Unusual radiologic findings in the thorax after radiation therapy. Radiographics. 2000 febrero; 20(1): 67-81.

58. Martínez Pérez C, Gumbau Puchol V, Basés Valenzuela C, Villalba Ferrer F, Fuster Diana C. Radiation 
pneumonitis after breast-conserving surgery for cancer. Cir Esp. octubre 2015; 93(8): e91-93.

59. Seo JB, Im J-G, Goo JM, Chung MJ, Kim M-Y. Atypical Pulmonary Metastases: Spectrum of Radiologic Findings. RadioGraphics. 2001 marzo 1; 21(2): 4034017.

60. Goldsmith HS, Bailey HD, Callahan EL, Beattie EJ. Pulmonary lymphangitic metastases from breast carcinoma. Arch Surg. 1967 abril; 94(4): 483-488.
61. Castañer E, Gallardo X, Pallardó Y, Branera J, Cabezuelo M, Mata J. Diseases affecting the peribronchovascular interstitium: CT findings and pathologic correlation. Current problems in diagnostic radiology. 2005 marzo 1; 34(2): 63-75.

62. Brown K, Mund DF, Aberle DR, Batra P, Young DA. Intrathoracic calcifications: radiographic features and differential diagnoses. Radiographics. 1994 nov; 14(6): 1247-1261. 